\title{
Wildfire Smoke Particle Properties and Evolution, from Space-Based Multi-Angle Imaging
}

\author{
Katherine Junghenn Noyes ${ }^{1, *}$, Ralph Kahn ${ }^{2}{ }^{-0}$, Arthur Sedlacek ${ }^{3}{ }^{\circledR}$, Lawrence Kleinman ${ }^{3}$, \\ James Limbacher ${ }^{2,4,5}$ and Zhanqing $\mathrm{Li}^{1,6}$ \\ 1 Department of Atmospheric and Oceanic Science, University of Maryland, College Park, MD 20742, USA; \\ zhanqing@umd.edu \\ 2 Earth Science Division, NASA Goddard Space Flight Center, Greenbelt, MD 20771, USA; \\ ralph.a.kahn@nasa.gov (R.K.); james.limbacher@nasa.gov (J.L.) \\ 3 Environmental and Climate Sciences Department, Brookhaven National Laboratory, Upton, NY 11973, USA; \\ sedlacek@bnl.gov (A.S.); kleinman@bnl.gov (L.K.) \\ 4 Science Systems and Applications Inc., Lanham, MD 20706, USA \\ 5 Department of Meteorology and Atmospheric Science, the Pennsylvania State University, \\ State College, PA 168026, USA \\ 6 Earth System Science Interdisciplinary Center, College Park, MD 20740, USA \\ * Correspondence: junghenn@umd.edu
}

Received: 30 January 2020; Accepted: 26 February 2020; Published: 29 February 2020

check for updates

\begin{abstract}
Emitted smoke composition is determined by properties of the biomass burning source and ambient ecosystem. However, conditions that mediate the partitioning of black carbon (BC) and brown carbon $(\mathrm{BrC})$ formation, as well as the spatial and temporal factors that drive particle evolution, are not understood adequately for many climate and air-quality related modeling applications. In situ observations provide considerable detail about aerosol microphysical and chemical properties, although sampling is extremely limited. Satellites offer the frequent global coverage that would allow for statistical characterization of emitted and evolved smoke, but generally lack microphysical detail. However, once properly validated, data from the National Aeronautics and Space Administration (NASA) Earth Observing System's Multi-Angle Imaging Spectroradiometer (MISR) instrument can create at least a partial picture of smoke particle properties and plume evolution. We use in situ data from the Department of Energy's Biomass Burning Observation Project (BBOP) field campaign to assess the strengths and limitations of smoke particle retrieval results from the MISR Research Aerosol (RA) retrieval algorithm. We then use MISR to characterize wildfire smoke particle properties and to identify the relevant aging factors in several cases, to the extent possible. The RA successfully maps qualitative changes in effective particle size, light absorption, and its spectral dependence, when compared to in situ observations. By observing the entire plume uniformly, the satellite data can be interpreted in terms of smoke plume evolution, including size-selective deposition, new-particle formation, and locations within the plume where $\mathrm{BC}$ or $\mathrm{BrC}$ dominates.
\end{abstract}

Keywords: biomass burning; remote sensing; MISR; smoke plumes; aerosol particle properties; aerosols; BBOP; multi-angle; multi-spectral; wildfire

\section{Introduction}

Wildfires are significant emitters of trace gases and aerosols that impact local air quality, and they can affect regional- and global-scale radiation budgets, cloud properties, and the water cycle. As such, adequately representing wildfire smoke plumes is an important consideration in climate and air quality modeling. In addition to dust storms, wildfires are the most significant sources of light-absorbing aerosols globally, specifically involving brown carbon (BrC) and black carbon (BC), 
as well as purely scattering aerosols, all of which have wide-ranging environmental impacts. Smoke aerosols that escape the planetary boundary layer (PBL) have the potential to stay aloft for several days or more, altering the regional radiative budget on time scales that can extend beyond the age of the fire itself and can affect air quality hundreds of kilometers downwind [1,2]. These particles also have the potential to act as cloud-condensation nuclei (CCN), resulting in aerosol-cloud interactions that can alter cloud reflectivity, cloud lifetime, and the frequency of precipitation [3-6].

The fuel type and amount, fire regime, and meteorology are known to affect smoke plume aerosol composition, with evidence indicating systematic differences in particle size distribution, particle light absorption, and the spectral dependence of absorption (e.g., References [7-10]). Although the dominant absorbing aerosol in biomass burning smoke is often BC, which is highly absorbing across all visible wavelengths, there is a variable fraction of $\mathrm{BrC}$ as well, which is usually less absorbing overall and exhibits stronger absorption at shorter wavelengths. For example, studies suggest higher BrC fractions in smoke plumes from smoldering than from flaming fires [11-13]. However, we do not yet have much understanding, even qualitatively, relating fire type to smoke particle speciation, nor of the fire-type-specific properties of $\mathrm{BrC}$, which vary greatly (e.g., Reference [14]). Furthermore, the mixing state of biomass burning (BB) aerosol particles is dynamic, changing with time and distance from the source, as they interact with water vapor, trace gases, and other particles during aging. For example, aerosols can oxidize in the presence of water vapor and other gaseous compounds, increasing the single scattering albedo (SSA) and possibly altering hygroscopicity so that they become more effective CCN. Larger particles might experience preferential gravitational settling, leading to an aerosol size distribution that is both narrower and, on average, smaller. Coatings deposited on particles increase their size, which, in turn, can increase scattering efficiency and enhance SSA as the plume ages [14,15]. Coatings deposited on BC particles can sometimes enhance light absorption through a lensing effect. As a plume cools, increased ambient relative humidity can result in increased particle hydration, SSA, and mean diameter. Gas-to-particle conversion can also occur where volatile organic compounds (VOCs) or $\mathrm{SO}_{2}$ emissions are present, which can produce very small and bright aerosols that might subsequently coagulate with primary aerosols. These mechanisms can occur in combinations that change on relatively short temporal and spatial scales. The variable nature of BB particles means that smoke plume radiative and other environmental impacts are far from uniform or predictable at present, especially as the dominant factors mediating particle aging are uncertain.

Significant efforts were made in recent years to observe smoke particle properties in situ with laboratory experiments, stationary observation sites (e.g., Reference [16]), and aircraft field campaigns. Recent field campaigns in the United States (US) include the Department of Energy's Biomass Burning Observation Project (BBOP) [17,18] and the National Aeronautics and Space Administration (NASA)'s Studies of Emissions and Atmospheric Composition, Clouds, and Climate Coupling by Regional Surveys (SEAC ${ }^{4} \mathrm{RS}$ ) [19]. These experiments studied both wildfire gas and particle-phase plume chemistry in great detail; in many cases, they were able to detect and measure different aerosol compositions within wildfire plumes (e.g., References [20-22]). The in situ observations provide data for only a small set of BB smoke cases, and in themselves do not allow for statistical characterization of emitted and evolved smoke. They do, however, provide considerable detail about aerosol microphysical properties, such as SSA and size distribution, which, in the past, were comparatively less well represented in satellite retrievals and models.

Due to the observational limitations mentioned above, much is unknown about the temporal and spatial distribution of fire-generated particle types and their aging. To date, most climate models do not discriminate between $\mathrm{BC}$ and $\mathrm{BrC}$ even though these particles display distinctly different physical, chemical, and optical properties (e.g., References [14,23]). Models are also uncertain about the role wildfire smoke plays in the aerosol-cloud interaction. Better characterization of BB aerosol properties is important to climate modeling, as it can improve our ability to quantify the radiative impacts of wildfires, which are expected to increase in frequency and intensity with global warming. 
Such increases would result in increased BB aerosol loading in the free troposphere, potentially causing more intense and longer-lasting environmental effects.

Until recently, satellite remote sensing data were relatively unhelpful in painting a sufficiently detailed, large-scale picture of aerosol properties. Early work focused primarily on retrieving the optical depth of ultraviolet (UV)-absorbing species, with considerable uncertainties due to sensitivity of the results to the vertical distribution of the smoke and the contributions of other aerosol types [24,25]. With the help of newly developed techniques, we are now in a position to improve our characterization of BB particles globally, and to explore the factors that control emitted and evolved BB particle properties (e.g., Reference [26]). In the current paper, we demonstrate several such techniques that leverage the multi-angle, multi-spectral measurements from the Multi-Angle Imaging Spectrometer (MISR) instrument aboard the NASA Earth Observing System's Terra satellite. The methods rely on retrievals from the MISR Interactive Explorer (MINX) tool to calculate plume heights and associated wind vectors [27], and the MISR Research Aerosol (RA) retrieval algorithm to characterize particle properties [28,29]. Recently, changes in particle size and light absorption observed with the RA were associated with particle coalescence, hydration, oxidation, gravitational sorting, and other processes in volcanic plumes [30-34]. Here, we both demonstrate the strengths and limitations of the MISR RA in retrieving wildfire smoke plume particle properties and explore the degree to which the results can go further than in situ observations in providing information on the entirety of the plume and its immediate surroundings. As the signal/noise for particle property retrievals is highest when the aerosol optical depth (AOD) is substantial [35], aerosol plumes are especially good targets for such analysis.

The goal of the current paper is to explore the degree to which these MISR methods can qualitatively describe plume particle characteristics, setting the stage for future work at developing a global climatology of BB aerosol plume properties and processes. A partial validation of the RA is conducted here with the aim of placing on firmer ground MISR retrievals of smoke plumes that are less well constrained by field observations. This is done primarily with data obtained during the BBOP campaign, on the 21 August 2013 flight through the Government Flats Complex Fire in northern Oregon, for which there was a near-coincident MISR overpass ( $\sim 2 \mathrm{~h}$ difference). Additional case studies presented here, having larger time differences between aircraft and satellite observations, bolster the comparison efforts and illustrate how the RA can help create a timeline of plume particle evolution, especially when combined with other coincident and noncoincident observations.

Data sources and analysis methods are outlined in Section 2. Section 3 presents our analyses of the similarities and differences between the RA and aircraft observations for the Government Flats Complex Fire, and briefly summarizes results for two additional BBOP campaign fires for which the aircraft and MISR observations were $\sim 24 \mathrm{~h}$ apart. The aerosol property differences determined from remote sensing illustrate how unique data signatures can point to certain aerosol aging processes and plume evolution mechanisms. Finally, conclusions and plans for future work are given in Section 4 .

\section{Materials and Methods}

Any comparison between satellite data and in situ observations is inherently challenging. The main obstacles are as follows: (1) satellite measurements probe large atmospheric volumes at comparatively low spatial resolution $(\sim 1 \mathrm{~km})$, whereas in situ observations are collected at higher spatial resolution $(\sim 10-100 \mathrm{~m})$, but cover only a fraction of the area seen from space, often lacking context and making large-scale averaging and interpreation difficult; (2) satellite observations of the atmosphere are affected by the presence of clouds, sun elevation effects, surface reflectance contributions, instrument degradation, and errors/assumptions made in the retrieval algorithms; (3) in situ instruments are subject to their own measurement uncertainties, such as sample inlet cut-off issues, typically requiring pre- or post-flight calibration; these measurements usually rely heavily on human operation, which reduces standardization; (4) passive remote sensing provides indirect measurements of column-integrated quantities that are not vertically resolved in most cases, whereas in situ suborbital data provide direct 
measurements, typically at specific points in three-dimensional (3D) space, making direct comparisons with satellite observations impossible for many variables.

For the current study, we face the additional challenge of time differences on the order of hours to a day between the satellite and in situ observations. The sampling differences and limitations of each dataset determine how the comparisons have to proceed. For example, the BBOP instruments may be capable of finding extreme values, even if they sample only a small portion of the plume, whereas MISR averages the signal over $\sim 1.1 \mathrm{~km}$ or more horizontally, and vertically over the column. Likewise, MISR is capable of seeing more area and may find different signals in parts of the plume that were missed by the aircraft. We address these issues by (1) focusing the comparison between the satellite and aircraft data on the general trends in aerosol properties along the length of the plumes, rather than focusing on the absolute values of those properties at particular locations, and (2) considering the possibility that differences in spatial and temporal sampling between the data might contribute to some observed differences in reported aerosol properties. Because smoke plume particle properties often evolve rapidly only a short time after they are emitted, where possible, we compare locations sampled by the aircraft and satellite of similar estimated plume age.

\subsection{Case Selection and Fire Properties}

Fire properties (i.e., burning characteristics, fuel type, etc.) can change dramatically over short time periods, making it difficult to compare in situ observations with satellite observations if there is a significant time difference. Thus, only flights that were coincident or near-coincident with the MISR observations can be used for the primary validation study. Among the BBOP flights, only one was near-coincident with MISR: the 21 August 2013 flight through a smoke plume in northern Oregon dubbed the Government Flats Complex Fire; the flight began approximately $2 \mathrm{~h}$ after MISR observed the area (Figure 1, Table 1). During the time between observations, plume geometry changed noticeably, most likely as a result of wind-driven advection. However, as shown later, plume particle properties still correlate reasonably well, especially for plume elements of similar age.

Table 1. Flight dates, times, and locations compared with dates and times of the Multi-Angle Imaging Spectroradiometer (MISR) overpass of the same area. Positive time delays between satellite and aircraft observations indicate the satellite observed the fire after the aircraft, whereas negative numbers mean the satellite completed its overpass first. The last flight, on 21 August, is the focus of the validation portion of the study. UTC-Universal Coordinated Time.

\begin{tabular}{|c|c|c|c|c|c|c|c|}
\hline \multirow[b]{2}{*}{ Fire Identifier } & \multicolumn{3}{|c|}{ Aircraft Observations } & \multicolumn{3}{|c|}{ MISR Observations } & \multirow[b]{2}{*}{$\begin{array}{c}\text { Approximate } \\
\text { Delay (h) }\end{array}$} \\
\hline & $\begin{array}{l}\text { Date } \\
\text { (UTC) }\end{array}$ & $\begin{array}{c}\text { Start } \\
\text { Time-End } \\
\text { Time (UTC) }^{\text {a }}\end{array}$ & Location & $\begin{array}{c}\text { Date } \\
\text { (UTC) }\end{array}$ & $\begin{array}{c}\text { Orbit; } \\
\text { Block (s) }\end{array}$ & $\begin{array}{l}\text { Time } \\
\text { (UTC) }\end{array}$ & \\
\hline Colockum Tarps & $26 / 7 / 13$ & 20:00-22:20 & $\begin{array}{c}\text { Southern } \\
\text { central WA }\end{array}$ & $7 / 27 / 13$ & $\begin{array}{l}72382 ; \\
53-54\end{array}$ & $19: 13$ & +23 \\
\hline Douglas Complex & 06/8/13 & $19: 30-21: 00$ & $\begin{array}{l}\text { Southern } \\
\text { coastal OR }\end{array}$ & $8 / 5 / 13$ & $\begin{array}{c}72513 ; \\
56\end{array}$ & 19:08 & -23 \\
\hline Government Flats & $21 / 8 / 13$ & $21: 20-22: 30$ & $\begin{array}{l}\text { Northern } \\
\text { central OR }\end{array}$ & $8 / 21 / 13$ & $\begin{array}{c}72746 ; \\
54\end{array}$ & $19: 07$ & -2 \\
\hline
\end{tabular}

${ }^{a}$ Indicates the approximate time range that the aircraft was actively observing the smoke plume(s) rather than the total flight time.

The second phase of this study uses the same type of data from other BBOP flights that took place approximately one day apart from MISR overpasses, the Colockum Tarps Fire and the Douglas Complex Fire (Table 1). Although these cases are less useful for validating the RA, they serve here as examples of the versatile and fluid nature of BB aerosol microphysical and optical properties. They also demonstrate the potential of the RA as a tool that both complements and enhances knowledge gained from in situ observations of wildfire smoke plumes. 


\subsection{MISR}

The unique multi-angle imaging capability of the MISR instrument [36] enables height and motion vector retrievals for clouds and aerosol plumes. Plume height is retrieved geometrically, based on the parallax of contrast features within the plume as observed in the multi-angle views. As such, plume features must have sufficient optical thickness and contrast, relative to the surface, to obtain plume height with this method. The retrievals are nicely accomplished by the MISR Interactive Explorer (MINX) software tool [27,37], which was used to derive stereo heights and wind vectors for plumes in this study. With MINX, heights and winds are retrieved locally by first manually defining the plume source, plume extent, and wind direction from the MISR imagery. MINX was used in a variety of studies, including but not limited to retrieving heights and winds for volcano, wildfire, and dust plumes [27,30,32-34,38-43]. Retrieved plume height and wind vectors help constrain aerosol transport modeling used to determine smoke source and age, and they can indicate whether the plume was injected above the PBL. The MINX analysis also provides some initial insight into the quality of the viewing conditions, as plumes lacking a clear source or easily identifiable wind direction in the satellite imagery can result in low-confidence height retrievals. In addition, if the plume height is above about $2 \mathrm{~km}$, the MISR images must be co-registered at the median plume height rather than at ground level to maximize aerosol-type retrieval performance when subsequently using the RA.

The MISR RA $[28,29]$ was used to constrain aerosol optical depth (AOD), as well as particle extinction Ångström exponent (ANG), single scattering albedo (SSA), and shape, all indicative of "aerosol type." A wide variety of aerosol components, each having different microphysical properties, can be included in the RA climatology, depending on the intended use of the algorithm (e.g., volcanic plumes, dust plumes, pollution, or wildfire plumes). The particle property information content of MISR observations is qualitative, amounting to three to five size bins (e.g., "small," "medium," and "large"), two to four bins in SSA, and spherical vs. randomly oriented non-spherical particle shapes, under good but not necessarily ideal retrieval conditions $[35,44]$.

In this work, we refer to the retrieved information on particle size and light absorption as the retrieved effective particle size (REPS; $\mu \mathrm{m}$ ) and the retrieved effective particle absorption (REPA; dimensionless), respectively. Particle size and light absorption derived from the satellite data are based on column-integrated, optical measurements rather than from direct sampling; thus, these terms help reflect both the measured content and the limitations of the retrieved quantities. Particle property information is diminished when the mid-visible AOD is below about 0.15 or 0.2 , but this is not an issue for well-defined smoke plumes. For the current study, we included one non-spherical component (a soil or dust grain optical analogue, based on an optical model derived by Lee et al. [45]) and 16 spherical components covering a range of sizes and SSA values (Table 2). For absorbing aerosols, the RA further classifies particle type according to flat or steep spectral dependence, where "flat" aerosols display little to no spectral variation in absorption and represent urban pollution or BC particles, whereas "steep" aerosols have greater absorption at shorter wavelengths and are more akin to $\mathrm{BrC}$ from wildfire smoke $[8,14,28,46]$. For each MISR pixel, the RA calculates component AOD values such that the simulated top-of-atmosphere (TOA) reflectances best match the MISR multi-angle, multi-spectral observations. This method was used for global aerosol typing [35] and for characterizing particle type in volcanic plumes $[30,33,34]$. Furthermore, along-plume changes in AOD, REPS, and REPA combined with available meteorological data and MINX stereo heights can provide insight into the relevant aging mechanisms for a plume observed under good retrieval conditions. For example, constant or increasing AOD accompanied by decreasing REPS can indicate the formation of secondary aerosols. Conversely, constant AOD accompanied by increasing REPS may indicate particle aggregation. Decreasing AOD accompanied by decreasing REPS may indicate size-selective dilution. These and other patterns were observed with MISR in volcanic plumes [34].

The operation of the RA was described by Limbacher and Kahn $[28,29]$. Recently, several advancements were made to the RA that increase particle property sensitivity, especially for over-land retrievals, and are leveraged in the current study. Most importantly, the RA uses 
prescribed land-surface reflectances from the Moderate Resolution Imaging Spectroradiometer (MODIS) Multi-Angle Implementation of Atmospheric Correction (MAIAC) [47]. In some previous RA versions, the surface reflectances were retrieved by the RA itself, which made it more difficult to separate the surface from atmospheric contributions, especially for optically thick, elevated plumes [44]. Secondly, the TOA reflectances are also now co-registered at the plume height, allowing results to be keyed to various heights rather than assuming confinement to the near-surface boundary layer. Thirdly, in evaluating the retrieval cost function, the algorithm now weights each channel (band and camera) based on the AOD retrieved when each aerosol mixture is assumed. The weights are normalized such that the mean value is one. This allows for effective use of the MISR near-infrared (NIR) band, which improves retrieval sensitivity to large particles. Specifically, when the surface reflectance is high in the NIR, which is often the case over land, the aerosol retrieval in that channel is likely to be poor. However, the AOD required to match the observed reflectances will also be low due to the bright surface; thus, these channels are weighted less. Lastly, the number of iterations used to identify the best-fitting AOD was increased. For this work, we introduced a revised particle climatology in the RA that is more focused on biomass burning plumes than in previous versions, such as the one used by Flower and Kahn [32-34,41]. It offers a greater range of candidate spherical particle size and absorption combinations, and it is based on size and absorption ranges identified in a recent literature review of $\mathrm{BB}$ particle properties [14] and informed by particle properties retrieved in situ during recent aircraft field campaigns similar to BBOP; details of the 17-component optical and physical properties included are given in Table 2.

Table 2. MISR components from Research Aerosol (RA) retrieval results, using the algorithm version summarized in Section 2.2, with a 774-mixture climatology. SSA—single scattering albedo.

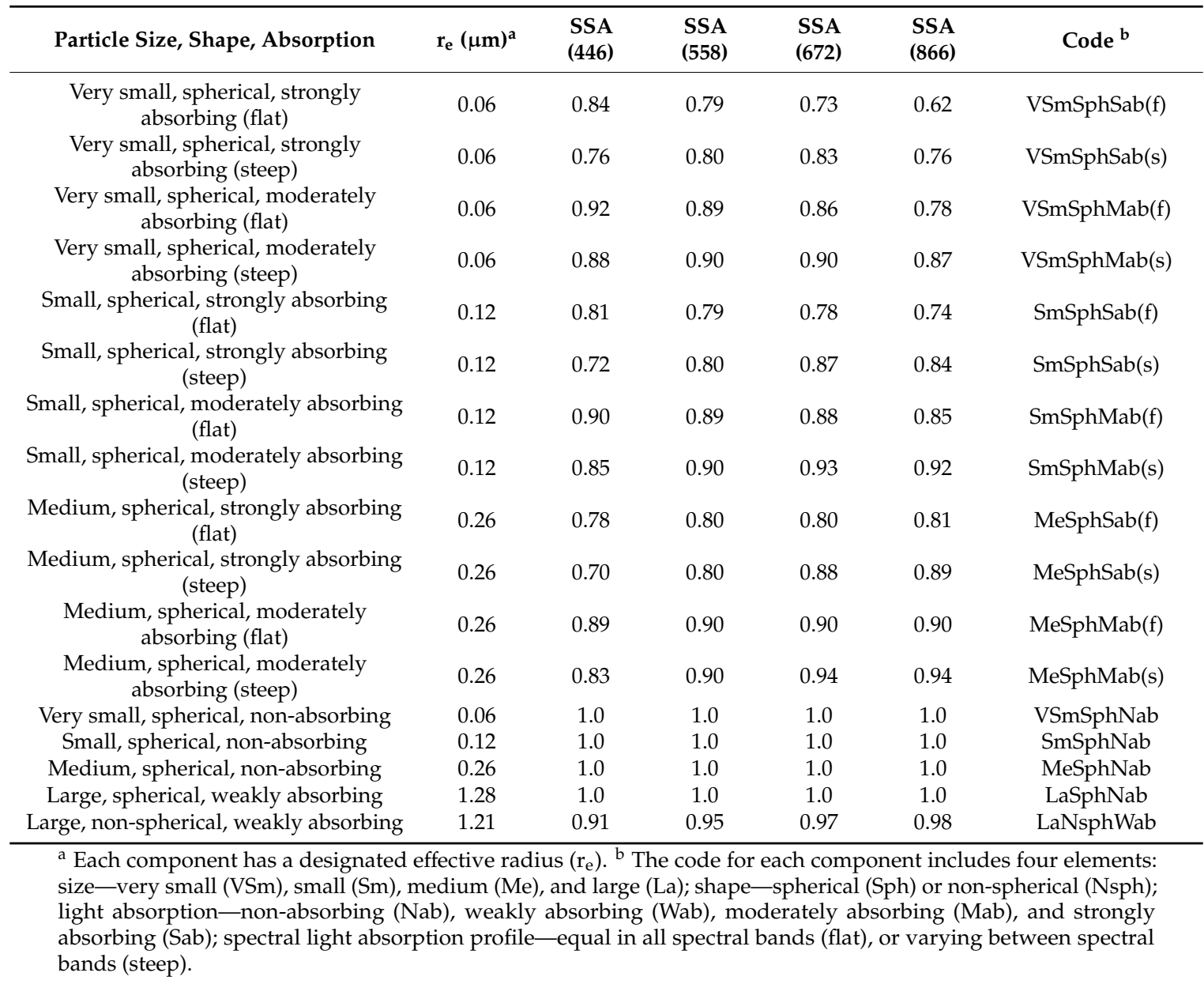




\subsection{Aircraft Data}

The BBOP campaign was conducted to enhance understanding of the atmospheric and environmental impacts of fire-generated particles, with particular focus on atmospheric chemistry [17,18]. From July to September 2013, the Department of Energy Gulfstream-1 (G-1) research aircraft flew through wildfire plumes in the Pacific Northwest, before moving to the lower Mississippi River Valley for the month of October to study agricultural burns. This field campaign was selected for the current study because it uniquely targeted the time evolution of smoke particles during the first few hours of atmospheric aging [18]. Given the large suite of instruments with which the G-1 aircraft was equipped, we leverage instrument data focused mostly on the aerosol size distribution and optical properties to which MISR is sensitive, but meteorological and atmospheric gas chemistry measurements are considered as well. For most measurements, the high temporal resolution (1-10 s, depending on the instrument) and varying amounts of instrument noise must be taken into account when making comparisons with the MISR RA results. We, therefore, smoothed the higher-frequency aircraft data (for the G-1 aircraft at cruising speed, $1 \mathrm{~s}$ translates to about $100 \mathrm{~m}$ ) by aggregating the sampled points into approximately $1.1-\mathrm{km}$ clusters, taking the median value of the measurements in each cluster, and assigning it to the median time, latitude, and longitude of the cluster. This facilitates both qualitative and quantitative analysis, as the RA operates at the $1.1-\mathrm{km}$ spatial resolution of MISR pixels.

\subsubsection{Aerosol Optical Properties}

We calculate SSA from the aerosol absorption and scattering coefficient measurements taken at 1-s intervals using the particle soot absorption photometer (PSAP) and nephelometer, respectively [48]. The nephelometer measures both total and hemispheric aerosol scattering at 450, 550, and $700 \mathrm{~nm}$ by detecting the aerosol-scattered light and subtracting that scattered by the air, $\mathrm{CO}_{2}$, and $\mathrm{SF}_{6}$ carrier gases. The nephelometer data provided were corrected using methods described by Anderson and Ogren [49], where details about the estimated instrument measurement uncertainty can also be found. The PSAP measures absorption continuously at three visible wavelengths by monitoring changes in transmittance through a filter, using a three-wavelength emitting light-emitting diode (LED) (461.6, 522.7, and $648.3 \mathrm{~nm})$. As filter-based instruments tend to overestimate aerosol absorption when scattering aerosols are also present, correction methods using scattering measurements from the nephelometer, based on those described by Bond et al. [50] and Ogren [51], were applied by the field scientists. The uncertainty of the PSAP measurements is ill-defined [52]. At some points in cleaner atmospheres where the nephelometer signal approached its detection limit, small negative scattering and absorption coefficients were reported. In these cases, any scattering coefficients $<-3 \mathrm{Mm}^{-1}$ and absorption coefficients $<-5 \mathrm{Mm}^{-1}$ were ignored.

To help identify $\mathrm{BrC}$, which is more absorbing in the UV than the mid-visible range and can lead to enhanced absorption when acting as a BC coating, we analyzed aerosol absorption measurements at $355 \mathrm{~nm}$ made by the photoacoustic soot spectrometer (PAS) [53], which made its maiden deployment during the BBOP campaign, and a photothermal interferometer (PTI) [54], operating at $532 \mathrm{~nm}$. Both the PAS and the PTI measure aerosol light absorption directly, by detecting air density fluctuations that occur when the air is heated due to laser light absorbed by the aerosols. The hallmark of these techniques is their immunity to aerosol light scattering; this is incredibly useful, as scattering is usually the dominant aerosol light-extinction mechanism. Relative to traditional filter-based instruments used to measure light absorption (e.g., the PSAP), these instruments exhibit a lower signal/noise ratio, but this problem is minimal for high smoke concentrations and was further reduced with the help of passive noise suppression methods (e.g., mufflers), which were employed after the first few flights. The aerosol light scattering and absorption measurements in the instrument have an uncertainty of $\pm 15 \%$. In previous studies, the uncertainty of the PTI technique was measured to be $10 \%$ (95\% confidence interval) when using $\mathrm{NO}_{2}$ as a calibration standard [54]. 


\subsubsection{Aerosol Microphysical Properties}

The Cloud and Aerosol Spectrometer (CAS) and Passive Cavity Aerosol Spectrometer (PCASP) calculate aerosol concentration within discrete size bins at 1-s intervals by measuring the intensity of light scattered by aerosols. In order to more directly compare size distributions from the flight data with that of the MISR RA retrievals, we summed the concentrations of multiple, smaller size bins into larger size categories for each instrument dataset, such that the median effective radius $\left(r_{e}\right)$ of each bin matches those defined by the RA aerosol climatology (Tables 2 and 3). Ranges do not match perfectly, as the RA is able to consider particle sizes at both extremes, whereas the aircraft instruments were limited to aerosols between 0.09 and $3.5 \mu \mathrm{m}$ in diameter. Where applicable, we used the median of the concentrations provided by the CAS and PCASP datasets (Table 3). Note that the comparisons made here are based on the qualitative size bins retrieved from MISR (Section 2.2); thus, our analysis is not affected by small differences in the size bin definitions.

The hygroscopicity of organic aerosols is a useful, qualitative indicator of $\mathrm{BC}$ mixing state and age, as hydrophobic $\mathrm{BC}$ aerosols normally tend to become more hydrophilic as oxidative processes produce sticky, coagulative coatings on the aerosol, often resulting in CCN activation [55]. To determine which aerosols could act as CCN, we used measurements at 1-s intervals from the Dual Column Cloud Condensation Nuclei Counter 200 (CCN-200), which uses a vertically oriented temperature gradient within a ceramic cylinder to create a supersaturated environment where water vapor can condense onto particles. The particles that grow to at least $0.75 \mu \mathrm{m}$ are considered activated and are then sized by the optical particle counter. The CCN-200 has two columns, one of which was kept at a supersaturation of $0.15 \%$ and the other at $0.25 \%$. Both were maintained at approximately $600 \mathrm{mbar}$ pressure throughout all the flights. The uncertainty for the instrument is less than $30 \%[56,57]$. When discussing CCN here, we refer to $\mathrm{CCN}$ that activate at $0.15 \%$ supersaturation as $\mathrm{CCN}_{15}$ and those that activate at $0.25 \%$ supersaturation as $\mathrm{CCN}_{25}$, although we focus on $\mathrm{CCN}_{15}$ to avoid redundancy.

Table 3. Size categories used to analyze the in situ observations. PCASP-Passive Cavity Aerosol Spectrometer; CAS-Cloud and Aerosol Spectrometer.

\begin{tabular}{|c|c|c|c|}
\hline Size Category & Size Range $\left(R_{e}, \mu \mathrm{m}\right)$ & Comparable RA Components & Instruments Used $^{\mathrm{a}}$ \\
\hline Very small & $0.045-0.09$ & $\begin{array}{l}\text { VSmSphSab(f), VSmSphSab(s), } \\
\text { VSmSphMab(f), VSmSphMab(s), } \\
\text { VSmSphNab }\end{array}$ & PCASP \\
\hline Small & $0.09-0.15$ & $\begin{array}{c}\text { SmSphSab(f), SmSphSab(s), } \\
\text { SmSphMab(f), SmSphMab(s), } \\
\text { SmSphNab }\end{array}$ & PCASP \\
\hline Medium & $0.15-0.46$ & $\begin{array}{c}\text { MeSphSab(f), MeSphMab(f), } \\
\text { MeSphSab(s), MeSphMab(s), } \\
\text { MeSphNab }\end{array}$ & PCASP \\
\hline Large & $0.46-1.725$ & LaSphNab, LaNsphWab & PCASP, CAS \\
\hline
\end{tabular}

a PCASP data from the July flight in this study were used with caution as they were collected with the calibration curve for water (1.33) instead of aerosol (1.58), and then converted in post-processing.

\subsubsection{Air and Particle Chemistry}

To account for plume dilution in our analysis, we applied $~ 1$-s carbon monoxide (CO) measurements from a Los Gatos Integrated Cavity Output Spectroscopy (ICOS) Analyzer with $\pm 5 \%$ uncertainty. $\mathrm{CO}$ and other trace gases are often used to account for dilution via a derived quantity known as the normalized excess mixing ratio (NEMR). The NEMR, defined as the ratio of the excess concentration of a species (compared to the background air) and the background-corrected value of $\mathrm{CO}$, was used to identify secondary formation of organic aerosols (OA) and inorganic aerosols in plumes using measurements of fine particle matter $\left(\mathrm{PM}_{2.5}\right)$ and OA mass [58].

To trace plume oxidation, we used nitrogen oxide measurements from a three-channel Oxides of Nitrogen Analyzer with $\pm 10 \%$ uncertainty. The extent of atmospheric processing was quantified using 
an independent proxy measurement for oxidation, defined here as $-\log _{10}\left[\mathrm{NO}_{\mathrm{x}} / \mathrm{NO}_{\mathrm{y}}\right]$ [59]. $\mathrm{NO}$, which is the steady-state mixture of $\mathrm{NO}$ and $\mathrm{NO}_{2}$, undergoes oxidation reactions to form $\mathrm{HNO}_{3}$, peroxyacetyl nitrate (PAN), and organic nitrates. The sum of $\mathrm{NO}_{\mathrm{x}}$ and these oxidation products is denoted $\mathrm{NO}_{\mathrm{y}}$, which is nearly conserved on timescales of less than one day. Although not quantitative, the $\mathrm{NO}_{\mathrm{x}} / \mathrm{NO}_{\mathrm{y}}$ clock was shown to correlate well with $\mathrm{O} / \mathrm{C}$ ratios that are commonly used to measure photochemical oxidation and secondary organic aerosol (SOA) formation [60].

We used refractory black carbon ( $\mathrm{rBC}$ ) mass and size measurements from the single-particle soot photometer (SP2) to help characterize particle type and mixing state. The SP2 derives mass concentrations of $\mathrm{rBC}$ by measuring the amplitude of incandescence signals produced as $\mathrm{rBC}$-containing particles traverse a continuous-wave laser beam [61,62] with a $\sim 25 \%$ level of uncertainty. At the same time, the instrument measures the size distribution $\left(\mathrm{dN} / \mathrm{d} \log \mathrm{D}_{\mathrm{p}}\right)$ of the $\mathrm{rBC}$-containing particles ranging from aerosols as small as $0.08 \mu \mathrm{m}$ to as large as $0.65 \mu \mathrm{m}$ in diameter. We approximate the size of $\mathrm{rBC}$-containing particles at a given point using the size bin at which the $\mathrm{dN} / \mathrm{d} \log \mathrm{D}_{\mathrm{p}}$ curve peaks, put here in terms of effective radius and denoted as $\mathrm{r}_{\mathrm{e}(\mathrm{BC})}$. It is important to remember that the particles are distributed around this value and, thus, actual sizes include particles that fall within an approximate range of $\pm 0.005 \mu \mathrm{m}$. It should also be noted that, unlike most other data, we did not smooth the SP2 data into $\sim 1.1-\mathrm{km}$ pixels, as its $10-\mathrm{s}$ temporal resolution $(\sim 1.0-1.3-\mathrm{km}$ spatial resolution) is already comparable to the spatial resolution of the MISR data. For the remainder of this paper, we refer to $\mathrm{rBC}$ using the more qualitative label "BC", as this is how we describe refractory black carbon particles when using satellite data.

\section{Results}

The Government Flats Complex was a large system of three lightning-sparked fires: the Government Flats fire, the Blackburn fire, and the Wells Road fire. They burned near Mt. Hood in Wasco County, Oregon from 16 August to 26 August 2013. Cumulatively, these fires burned over 11,350 acres of land, although the Blackburn fire was responsible for $98 \%$ of this area. According to the US Forest Service, the fuel model in this area was summer hardwood litter [63]. The plume produced by this fire complex was observed by MISR on 21 August 2013, at 19:07 Universal Coordinated Time (UTC), $2 \mathrm{~h}$ before the BBOP G-1 aircraft began sampling the same area; the aircraft continued sampling this plume for an additional hour. At both observation times, the plume displays unique aerosol optical and physical property patterns that vary with downwind distance. We divide the MISR-observed plume into four regions based on these patterns: a near-source region (designated region I), a near-downwind region (II), a mid-downwind region (III), and a far-downwind region (IV) (Figure 1a). We calculate the approximate age of the smoke at regional boundaries using the ratio of the along-plume distance and mean wind vectors in the area derived from MINX (see Supplementary Materials, Figure S1). Based on plume age calculated by Kleinman and Sedlacek [18], and similar trends in particle properties, the BBOP-observed plume was divided into regions of similar age (Figure 1b), although the aircraft did not sample the part of the plume corresponding to region IV in the MISR imagery. In this section, we compare the particle properties retrieved from space with those obtained in situ from the aircraft measurements, paying particular attention to the differences between these regions. We then apply this information to current knowledge on how different aging processes affect particle properties in order to infer the active mechanisms at hand.

Only observations taken within the plume boundaries seen in Figure 1 are included in our analysis, except when comparing measurements to background values. For the MISR dataset, the boundary is a user-drawn plume outline created during the MINX retrieval. Some areas of optically very thin smoke can be seen in the imagery outside the boundary, but MISR had difficulty performing retrievals beyond a certain distance downwind (where the plume becomes thin), as can be seen by the lack of MINX plume results, and as indicated by some empty pixels in the RA retrievals shown subsequently. For the BBOP dataset, the RGB MODIS-Aqua image, acquired about $2 \mathrm{~h}$ after the MISR overpass, was used to draw the plume outline (Figure 1b). However, significant cloud contamination made it 
challenging to determine exact boundaries in the two most downwind regions; thus, carbon monoxide and total aerosol count measurements from the aircraft were used to refine the shape (Figure $1 \mathrm{c}, \mathrm{d}$, respectively). This is also important, as plume geometry can change during the course of the flight itself; thus, the MODIS snapshot might not perfectly represent the plume as sampled by the aircraft, even without cloud contamination. Where applicable, all figures display the plume boundary as a dotted-line polygon and the dividing lines between regions as thin solid gray lines.
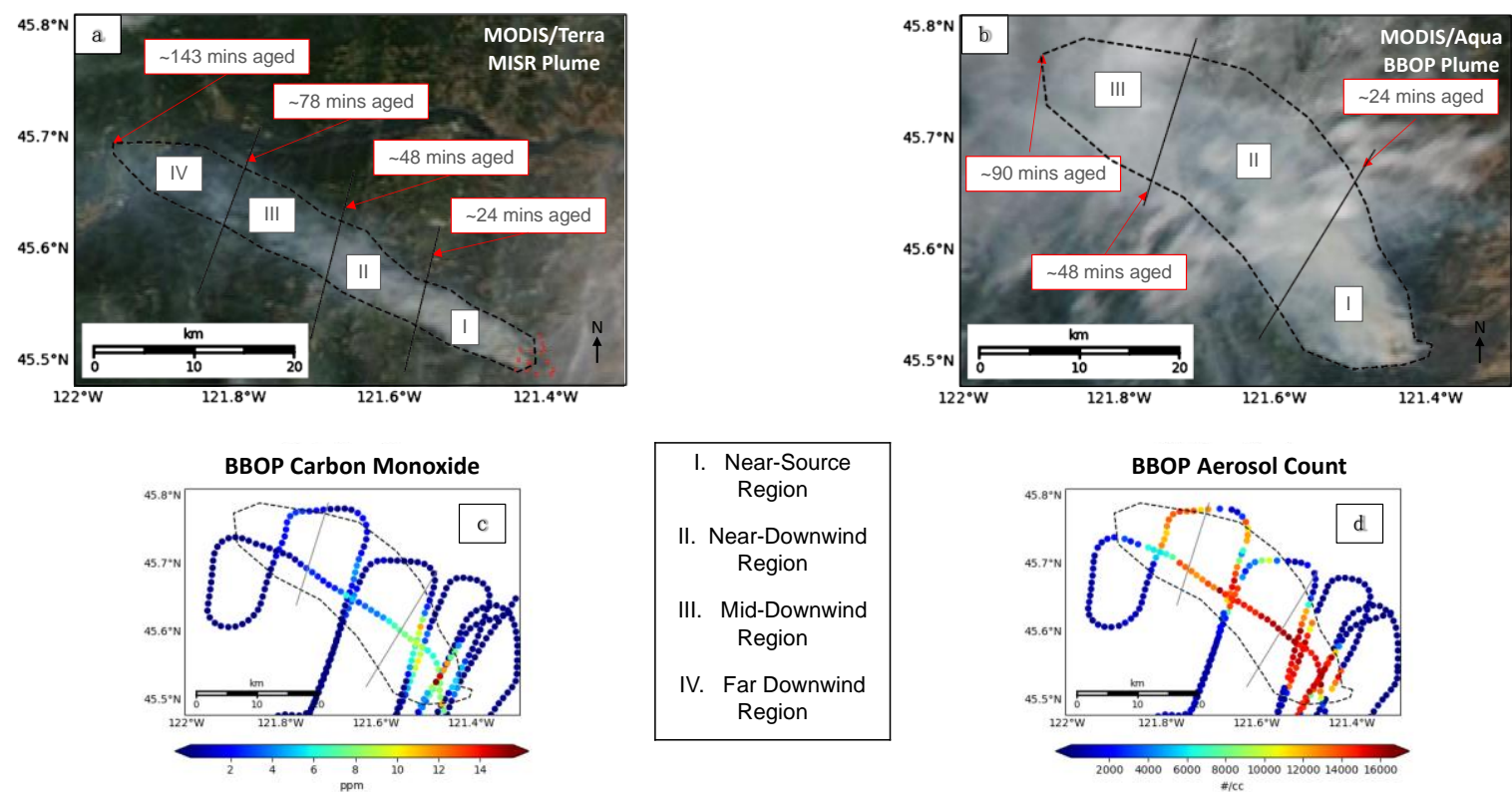

Figure 1. The Government Flats Complex Fire as seen on 21 August 2013: (a) at MISR overpass time (19:07 UTC; Moderate Resolution Imaging Spectroradiometer (MODIS) Terra red-green-blue (RGB) context image), and (b) during the Department of Energy's Biomass Burning Observation Project (BBOP) flight operations (20:49 UTC; MODIS Aqua RGB image; the aircraft flight began at 21:20 UTC). The red dots in Panel (a) indicate MODIS-identified hot spots, which are used to estimate source location. The dashed lines represent the plume outlines we use for analysis. At both observation times, the plume is divided into regions (I-IV) based on estimated plume age, to allow for easy, qualitative comparison of inter- and intra-plume properties. Panels (c) and (d) represent the aircraft in situ CO and total aerosol count measurements, respectively.

\subsection{In Situ Observations: A First Look}

We provide an overview of the aircraft observations first, with an emphasis on the differences in smoke properties between regions. Figures 2 and 3 illustrate, as latitude/longitude plots, the chemical, optical, and physical properties, measured using the methods described in Section 2.3. Each point represents the aggregated $\sim 1.1-\mathrm{km}$ median value of a given measurement (except for Figure 2c, which did not need to be aggregated, as discussed in Section 2.3.3). Table 4 quantifies the mean, standard deviation (SD or $\sigma$ ), and median values of the measurements from Figures 2 and 3 for each region, and a comprehensive discussion of these statistics can be found in the Supplementary Materials. 

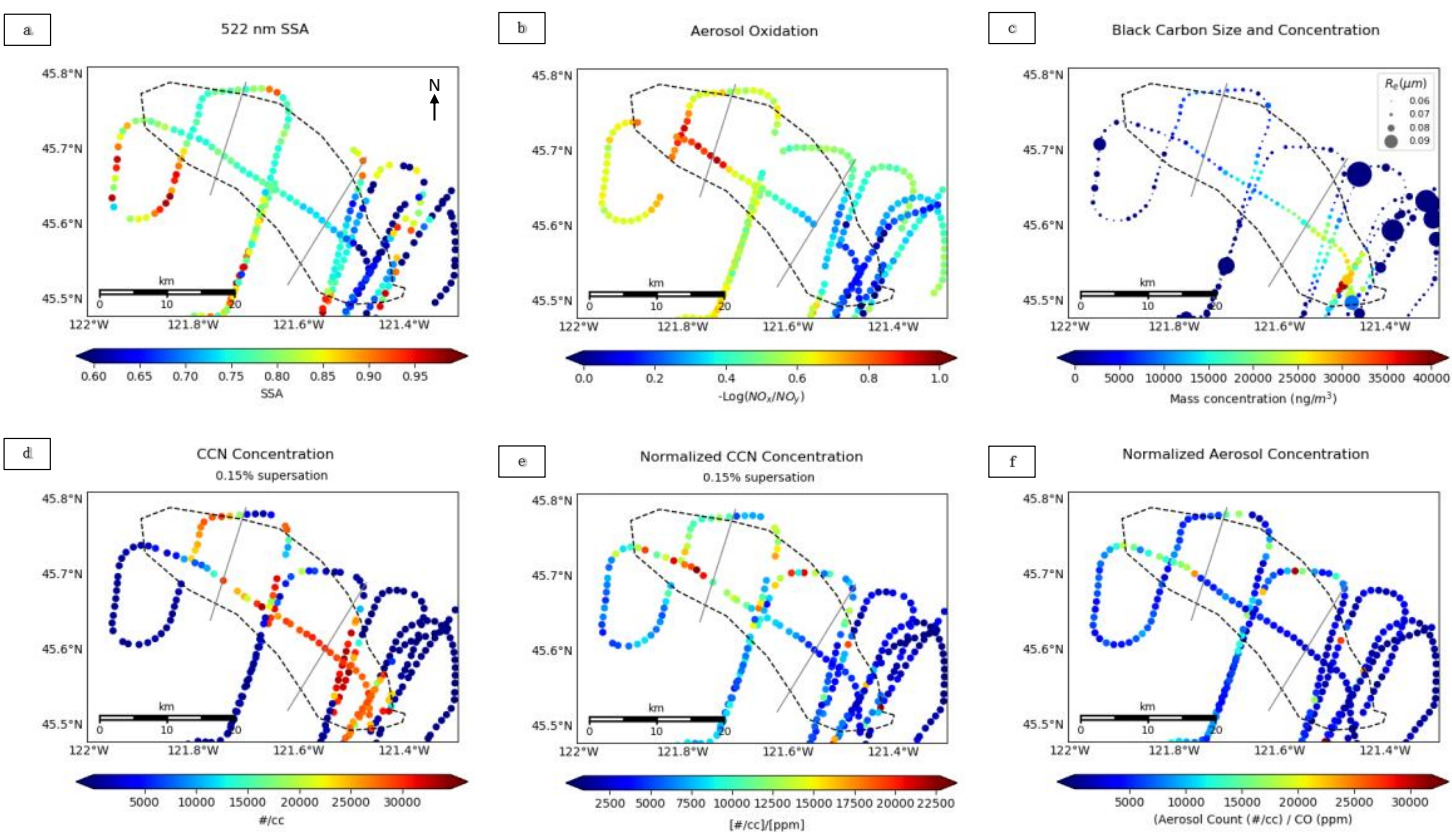

Figure 2. BBOP aircraft observations of the Government Flats Complex fire on 21 August 2013: (a) 522-nm SSA (particle soot absorption photometer (PSAP)/neph); (b) aerosol oxidation (derived from the three-channel Oxides of Nitrogen Analyzer); (c) mass concentration of black carbon (BC) and size of BC-containing particles (single-particle soot photometer (SP2)); (d) concentration of particles that can act as cloud-condensation nuclei $(\mathrm{CCN})$ at $0.15 \%$ supersaturation (CCN-200 instrument); (e) the $\mathrm{CCN}$ concentration divided by the $\mathrm{CO}$ concentration; (f) the total aerosol concentration divided by the CO concentration.
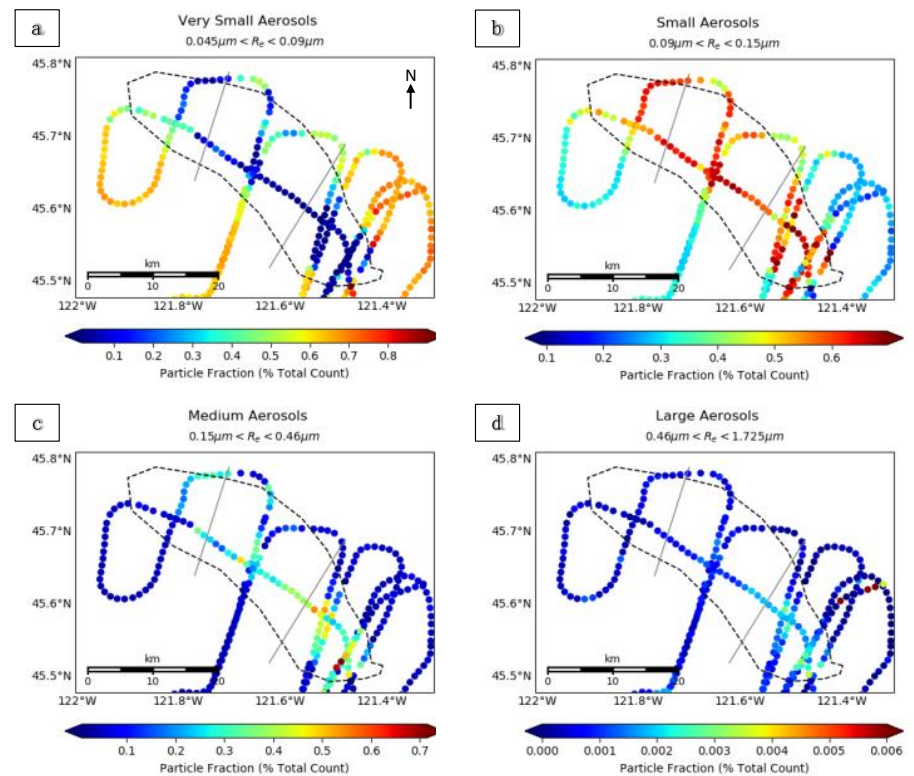

Figure 3. Fractional contributions (from zero to one) to the total aerosol count for (a) very small, (b) small, (c) medium, and (d) large aerosols in the Government Flats Complex Fire, as measured by the PCASP and CAS in situ instruments on 21 August 2013. The gray lines represent the boundaries between regions defined in Figure 1. Note: approximate size ranges are given above each plot, and the scales differ between categories. 
Table 4. Aircraft data: aerosol size, chemical, and physical properties for the Government Flats Complex Fire measured in situ.

\begin{tabular}{|c|c|c|c|c|}
\hline \multicolumn{2}{|c|}{ Plume Region: } & \multirow{2}{*}{$\begin{array}{c}\text { Near-Source (I) } \\
0.1250 \pm 0.1712 \\
0.03893\end{array}$} & \multirow{2}{*}{$\begin{array}{c}\text { Near-Downwind (II) } \\
0.1904 \pm 0.1626 \\
0.1121\end{array}$} & \multirow{2}{*}{$\begin{array}{c}\text { Mid-Downwind (III) } \\
0.2935 \pm 0.1573 \\
0.3473\end{array}$} \\
\hline Very small aerosols ${ }^{a}$ & $\begin{array}{l}\text { mean } \pm \sigma \\
\text { median }\end{array}$ & & & \\
\hline Small aerosols ${ }^{a}$ & $\begin{array}{l}\text { mean } \pm \sigma \\
\text { median }\end{array}$ & $\begin{array}{c}0.5662 \pm 0.1124 \\
0.5962\end{array}$ & $\begin{array}{c}0.5930 \pm 0.07029 \\
0.6096\end{array}$ & $\begin{array}{c}0.5609 \pm 0.1124 \\
0.5612\end{array}$ \\
\hline Medium aerosols $^{a}$ & $\begin{array}{l}\text { mean } \pm \sigma \\
\text { median }\end{array}$ & $\begin{array}{c}0.3072 \pm 0.1534 \\
0.3072\end{array}$ & $\begin{array}{c}0.2157 \pm 0.1144 \\
0.2383\end{array}$ & $\begin{array}{c}0.1452 \pm 0.09571 \\
0.09315\end{array}$ \\
\hline Large aerosols ${ }^{a}$ & $\begin{array}{l}\text { mean } \pm \sigma \\
\text { median }\end{array}$ & $\begin{array}{c}0.001549 \pm 0.0007137 \\
0.001502\end{array}$ & $\begin{array}{c}0.0008949 \pm 0.0004193 \\
0.0008090\end{array}$ & $\begin{array}{c}0.0004482 \pm 0.0002103 \\
0.0004333\end{array}$ \\
\hline $\mathrm{SSA}_{522}{ }^{\mathrm{b}}$ & $\begin{array}{l}\text { mean } \pm \sigma \\
\text { median }\end{array}$ & $\begin{array}{c}0.7001 \pm 0.07297 \\
0.7029\end{array}$ & $\begin{array}{c}0.7679 \pm 0.030083 \\
0.7605\end{array}$ & $\begin{array}{c}0.7814 \pm 0.03647 \\
0.7748\end{array}$ \\
\hline Oxidation ${ }^{\mathrm{c}}$ & $\begin{array}{l}\text { mean } \pm \sigma \\
\text { median }\end{array}$ & $\begin{array}{c}0.2018 \pm 0.1447 \\
0.2037\end{array}$ & $\begin{array}{c}0.5307 \pm 0.1400 \\
0.5318\end{array}$ & $\begin{array}{c}0.7855 \pm 0.1115 \\
0.8026\end{array}$ \\
\hline $\mathrm{rBC}_{\text {mass }} \mathrm{d}$ & $\begin{array}{l}\text { mean } \pm \sigma \\
\text { median }\end{array}$ & $\begin{array}{c}16,383.15 \pm 8494.77 \\
17,437.12\end{array}$ & $\begin{array}{c}8638.98 \pm 5765.73 \\
8164.26\end{array}$ & $\begin{array}{c}4805.65 \pm 3553.27 \\
4036.97\end{array}$ \\
\hline $\begin{array}{l}\text { rBC mass normalized } \\
\text { by } \mathrm{CO}^{\mathrm{e}}\end{array}$ & $\begin{array}{l}\text { mean } \pm \sigma \\
\text { median }\end{array}$ & $\begin{array}{c}8328.4 \pm 15,678 \\
2812.2\end{array}$ & $\begin{array}{c}5973.7 \pm 10,509 \\
3388.7\end{array}$ & $\begin{array}{c}4528.1 \pm 4298.5 \\
3416.7\end{array}$ \\
\hline$R_{e(B C)}{ }^{f}$ & $\begin{array}{l}\text { mean } \pm \sigma \\
\text { median }\end{array}$ & $\begin{array}{c}0.070 \pm 0.0064 \\
0.070\end{array}$ & $\begin{array}{c}0.065 \pm 0.0049 \\
0.065\end{array}$ & $\begin{array}{c}0.064 \pm 0.0060 \\
0.065\end{array}$ \\
\hline $\mathrm{CCN}_{15}{ }^{\mathrm{g}}$ & $\begin{array}{l}\text { mean } \pm \sigma \\
\text { median }\end{array}$ & $\begin{array}{c}24,273.13 \pm 9852.24 \\
27,578.10\end{array}$ & $\begin{array}{c}19,976.24 \pm 11,071.74 \\
24,810.73\end{array}$ & $\begin{array}{c}15,497.54 \pm 10,310.76 \\
12,212.83\end{array}$ \\
\hline $\begin{array}{c}\mathrm{CCN}_{15} \text { normalized } \\
\text { by } \mathrm{CO}^{\mathrm{h}}\end{array}$ & $\begin{array}{l}\text { mean } \pm \sigma \\
\text { median }\end{array}$ & $\begin{array}{c}5710.84 \pm 3566.64 \\
4716.05\end{array}$ & $\begin{array}{c}10,657.30 \pm 4390.24 \\
9408.83\end{array}$ & $\begin{array}{c}14,829.78 \pm 4112.40 \\
13,340.70\end{array}$ \\
\hline $\begin{array}{c}\text { Aerosol count } \\
\text { normalized by } \mathrm{CO}^{\mathrm{i}}\end{array}$ & $\begin{array}{l}\text { mean } \pm \sigma \\
\text { median }\end{array}$ & $\begin{array}{c}3844.60 \pm 4960.87 \\
2328.85\end{array}$ & $\begin{array}{c}7048.10 \pm 5861.56 \\
5015.14\end{array}$ & $\begin{array}{c}9465.11 \pm 5191.19 \\
7451.74\end{array}$ \\
\hline $\begin{array}{c}\text { BrC absorption } \\
\text { normalized by } \mathrm{CO}^{\mathrm{j}}\end{array}$ & $\begin{array}{c}\text { mean } \\
\text { median }\end{array}$ & $\begin{array}{l}172.39 \\
163.66 \\
\end{array}$ & $\begin{array}{l}216.97 \\
210.10 \\
\end{array}$ & $\begin{array}{l}207.14 \\
217.69 \\
\end{array}$ \\
\hline $\begin{array}{l}\text { 355-nm scattering } \\
\text { normalized by CO }\end{array}$ & $\begin{array}{c}\text { mean } \\
\text { median }\end{array}$ & $\begin{array}{l}1771.90 \\
1591.90\end{array}$ & $\begin{array}{l}2447.76 \\
2363.77\end{array}$ & $\begin{array}{l}2515.30 \\
2377.25\end{array}$ \\
\hline
\end{tabular}

${ }^{a}$ Fraction of total aerosol count, as measured by the PCASP and CAS instruments in accordance with Table $3 ;{ }^{\text {b }}$ As measured by the PSAP/neph; ${ }^{c}$ Defined as $-\log \left[\mathrm{NO}_{\mathrm{x}} / \mathrm{NO}_{\mathrm{y}}\right]$, using measurements provided by the three-channel Oxides of Nitrogen Analyzer, where 0 is fresh smoke and 1 is aged smoke; ${ }^{\mathrm{d}}$ As measured by the SP2, in ng $/ \mathrm{m}^{3}$; ${ }^{\mathrm{e}}$ The ratio of $\mathrm{BC}$ mass concentration $\left(\mathrm{ng} / \mathrm{m}^{3}\right)$ and $\mathrm{CO}(\mathrm{ppm}) ;{ }^{\mathrm{f}}$ As measured by the SP2, in terms of effective radius $\mathrm{R}_{\mathrm{e}}$ in $\mu \mathrm{m} ;{ }^{\mathrm{g}}$ The concentration (\#CC) of CCN that actived at $0.15 \%$ superstation, as measured by the CCN-200; ${ }^{\mathrm{h}}$ The ratio of $\mathrm{CCN}_{15}$ measured by the $\mathrm{CCN}-200$ instrument $(\# / \mathrm{cc})$ and $\mathrm{CO}$ concentration measured by the Los Gatos Integrated Cavity Output Spectroscopy (ICOS) Analyzer (ppm); ${ }^{i}$ The ratio of the total aerosol count from the PCASP/CAS instruments (\#/cc) and the CO concentration measured by the Los Gatos ICOS Analyzer (ppm); ${ }^{j}$ The residual of the ratio of 355-nm absorption (PAS; $\mathrm{Mm}^{-1}$ ) and CO concentration (Los Gatos ICOS Analyzer; ppm) and the ratio of 522-nm absorption (PTI; $\mathrm{Mm}^{-1}$ ) and CO concentration (Los Gatos ICOS Analyzer; ppm). Note that values only reflect data from the one along-plume transect. Standard deviations are not given as values were calculated by subtracting mean $\mathrm{BC}$ absorption from mean $\mathrm{BrC}$ absorption, rather than by the means of the residuals; ${ }^{\mathrm{k}}$ The ratio of 355-nm scattering (PAS; $\mathrm{Mm}^{-1}$ ) and CO concentration (Los Gatos ICOS Analyzer; ppm). Note that values only reflect data from the one along-plume transect. Standard deviations are not given as values were calculated by subtracting mean $\mathrm{BC}$ absorption from mean $\mathrm{BrC}$ absorption, rather than by the means of the residuals.

In general, the plume contains fresh, highly absorbing smoke near the source that becomes both increasingly bright $\left(\mathrm{SSA}_{522}\right)$ and oxidized $\left(-\log \left[\mathrm{NO}_{\mathrm{x}} / \mathrm{NO}_{\mathrm{y}}\right]\right)$ with downwind distance (Figure $2 \mathrm{a}, \mathrm{b}$, respectively). Both absolute and mean $\mathrm{CO}$-normalized $\mathrm{BC}$ mass concentration decrease along the length of the plume (Figure 2c, Table 4); however, rates of BC dilution vary between the plume center (no increasing dilution with downwind distance) and the plume edges (increasing dilution with downwind distance). The disparities between the median and mean values in Table 4, as well as the differences in sampling seen in Figure 2, illustrate this pattern. CO-normalized CCN and aerosol concentration both increase along the length of the plume, particularly in the southern flank of region III, where smoke is the most oxidized (Figure 2e-f). CAS and PCASP data indicate the plume is comprised almost entirely of particles with $r_{e}$ of $0.46 \mu \mathrm{m}$ or less (i.e., "very small," "small," and "medium" particles, similar to 
the aerosols of the same name identified within the MISR retrieval sensitivity limitations, discussed in Section 2.2 above). "Large" aerosols $\left(0.46 \mu \mathrm{m}<\mathrm{r}_{\mathrm{e}}<1.7 \mu \mathrm{m}\right)$ are essentially absent, never representing more than $0.35 \%$ of all particles, which is substantially below MISR retrieval sensitivity. Aerosol size decreases along the central plume transect, with the most dramatic decrease seen in the southern flank of region III (Figure 3). PTI (532 nm) and PAS (355 nm) absorption measurements used to distinguish spectrally flat from spectrally steep aerosols show that BC-only absorption (which is approximately equal at both wavelengths) declines more dramatically downwind than BrC-only absorption (the residual of 355-nm absorption minus 532-nm absorption), and that $\mathrm{CO}$-normalized BrC absorption and CO-normalized 355-nm scattering actually increase dramatically in region II (Table 4). In their final campaign report, Kleinman and Sedlacek [18] also found that CO-normalized BrC absorption and scattering increased after $\sim 30$ min of plume aging. Although particle size is known to influence the spectral slope of SSA, the observed jump in 355-nm absorption and scattering does not correlate with significant changes in particle size, and thus it is likely that particle composition is the dominant factor driving the observed changes.

The in situ data alone do not provide enough information to fully explain these changes in aerosol properties. However, from available observations, we suggest several potential processes that could be affecting the plume particle properties: (1) gravitational settling and/or dilution that leads to the preferential decrease in medium-size particle concentration and BC particle concentration in regions II and III compared to region I; (2) oxidation and/or SOA production, leading to increased hygroscopicity and decreased light absorption contributions in regions II and III; (3) changes in burning conditions at the source, which alter the emitted smoke properties, reflected in particle-type differences between regions. Gravitational settling cannot be confirmed by the in situ data acquired at a single elevation. Particle oxidation state can be measured in situ, but can only be inferred from remote sensing, e.g., based on decreasing particle light absorption, although particle hydration is also possible, especially if particle size increases, hydrophilic particles (e.g., $\mathrm{BrC}$ ) are present, and $\mathrm{RH}$ is high. If in situ measurements of particle size but not composition are available, the formation of secondary particles would have to be confirmed by total column measurements, as it is possible that decreases in particle size, as measured in situ, might instead be due to preferential gravitational settling of larger particles. However, the CO-normalized, absolute increase in small-particle concentration strongly supports the idea of particle formation in this case, as it indicates that dilution is minimal. Other particle evolution processes can occur, such as aggregation; however, based on the available in situ data, this does not seem likely here, unless it occurred very near source, where aerosol loading was extremely high. Changes in the burning conditions at the source cannot be confirmed or ruled out by remote sensing, and in situ measurements only allow us to infer the degree to which the fire may be changing. Several overlapping transects made by the BBOP aircraft at different times suggest measurements at a given distance from the source (i.e., similarly aged smoke at different times) are not dramatically different between these observations, indicating that changes in burning conditions may not be important here.

\subsection{Satellite Observations: Validation and Providing a Broader Context}

As demonstrated above, aircraft measurements provide highly detailed observations of the plume that allow us to identify general particle-type differences and to narrow down the list of potential aging mechanisms. However, the limited area sampled in situ across two hours, during which changes could have occurred, leaves us with an incomplete understanding of plume properties, and these data alone cannot resolve key uncertainties regarding the atmospheric particle processes that operated. Here, we provide an overview of the satellite observations, with the same emphasis on differences between regions as in Section 3.1, and we compare them with the aircraft measurements to assess the fidelity of the RA. We also demonstrate how the RA places in situ observations into a broader context, providing information critical for understanding the processes responsible for plume evolution.

Figure 4 contains standard MISR RA latitude/longitude plots of AOD, SSA, and ANG for the plume, with the MISR-MINX stereo heights included for reference. In addition to these, we map, 
in terms of both retrieved absolute AOD and AOD fractional component, the spectral dependence of aerosol light absorption via the separate sums of (1) retrieved spectrally flat (BC analog) and (2) spectrally steep (BrC analog) light-absorbing components (Figure 5a-d), (3) the retrieved aerosol shape, via the non-spherical component LaNsphWab (Figure 5e-f), and (4) further information on absorption via the sum of all non-absorbing components (Figure $5 \mathrm{~g}-\mathrm{h}$ ). These particle properties are, for the most part, neatly distinctive between the four plume regions, as discussed subsequently. It is important to reiterate that, when considering specific particle types (e.g., black carbon, brown carbon, dust, non-absorbing aerosols), the retrieved aerosol properties represent the optical equivalent of the aerosol present, i.e., the true aerosol is not necessarily a mixture of the specific components retrieved from among those in the RA climatology (e.g., Reference [30]). Table 5 quantifies the above-mentioned RA observations, giving the mean, standard deviation (SD or $\sigma$ ), and median for each region; a more in-depth analysis of these statistics can be found in the Supplementary Materials.
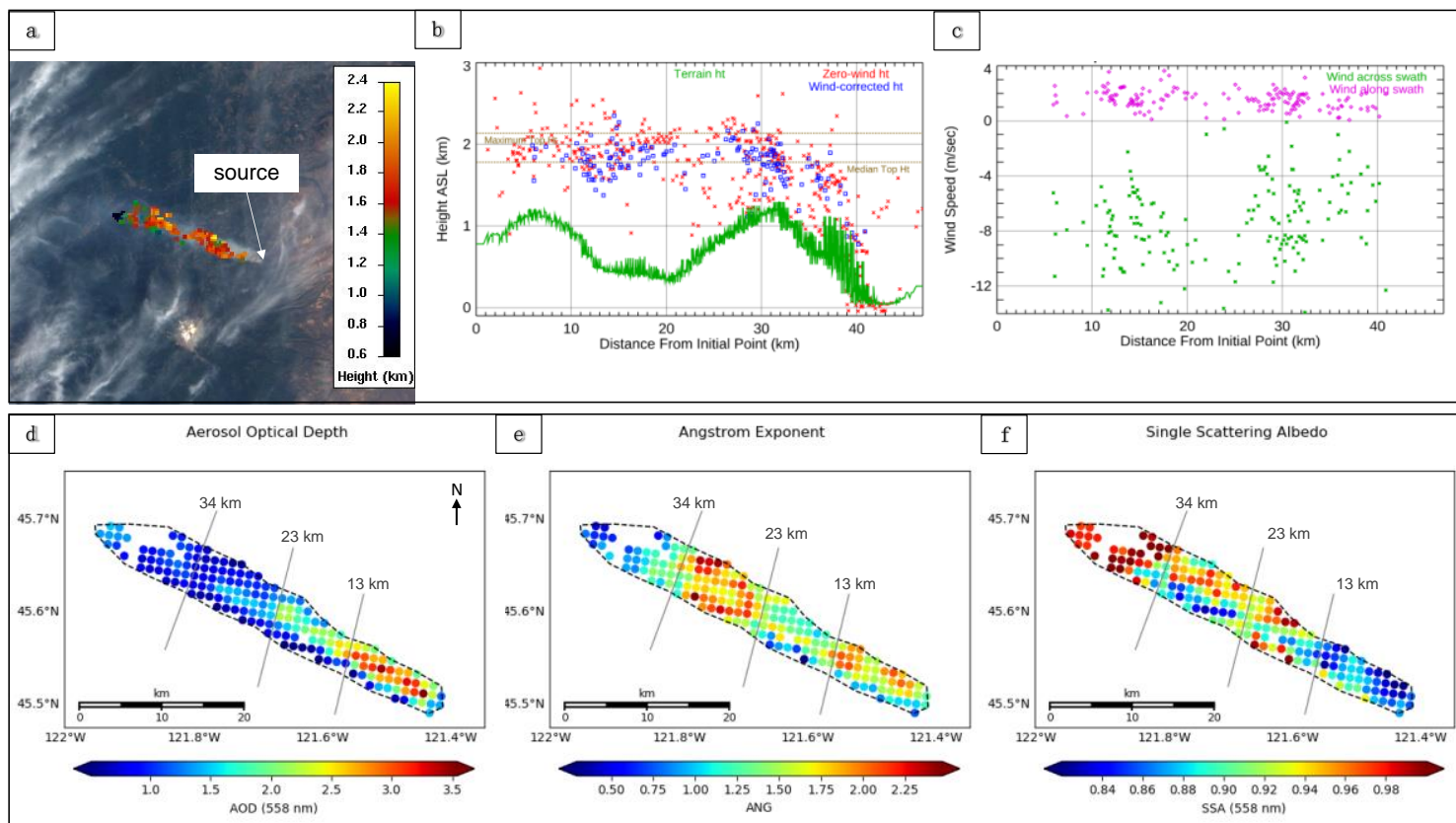

Figure 4. Plume properties for the Government Flats Complex Fire retrieved by MISR at 19:07 UTC (Orbit 72746, Path 45, Block 54) on 21 August 2013: (a) MISR Interactive Explorer (MINX) stereo height retrieval map; (b) MINX stereo height profile as a function of distance from the source, for both zero-wind (red) and wind-corrected (blue) analyses, with surface elevation indicated in green, (c) MINX-retrieved across-swath and along-swath wind vectors, and RA-derived (d) AOD at $558 \mathrm{~nm}$, (e) extinction ANG, and (f) SSA at $558 \mathrm{~nm}$. The transects for estimated plume ages corresponding to the regional boundaries in Figure 1 are indicated with thin gray lines in panels $d-f$.

The MISR-MINX stereo heights indicate the plume is concentrated mostly within $2 \mathrm{~km}$ above sea level (ASL), with a median height of $1.78 \mathrm{~km}$ and a maximum height of $2.13 \mathrm{~km}$ (Figure $4 \mathrm{a}-\mathrm{b}$ ). The RA-retrieved particle properties indicate peak AOD of up to 3.5 near the source, decreasing with downwind distance to a minimum of $\sim 0.5$ in some pixels within the area we defined as the observable plume in the satellite imagery (Figure $4 \mathrm{~d}$ ). The plume REPA also decreases significantly with downwind distance, and SSA increases from $<0.84$ near the source to nearly 1.0 in region IV. Although most particles can be considered fine mode, having ANG > 1, REPS increases slightly in region II, dramatically decreases in region III, and then dramatically increases again in region IV (some pixels having ANG $<1$ ), indicating significant changes in particle size throughout the length of the plume. Component analysis suggests that smoke near the source is largely a BC-like mixture, but that subsequent regions transition to mixtures interpreted as mostly non-absorbing and $\mathrm{BC}$ particles in 
region II, then non-absorbing, $\mathrm{BC}$, and $\mathrm{BrC}$ particles in region III, and non-absorbing and dust- or soil-like optical analogues in region IV (Figure 5). Bear in mind that these retrieved component AOD values and fractions represent an interpretation of the MISR column-integrated reflectances in terms of the components included in the RA (Table 2), whereas the REPS and REPA are less dependent on algorithm assumptions. This is one reason why validation with the in situ data is so important.

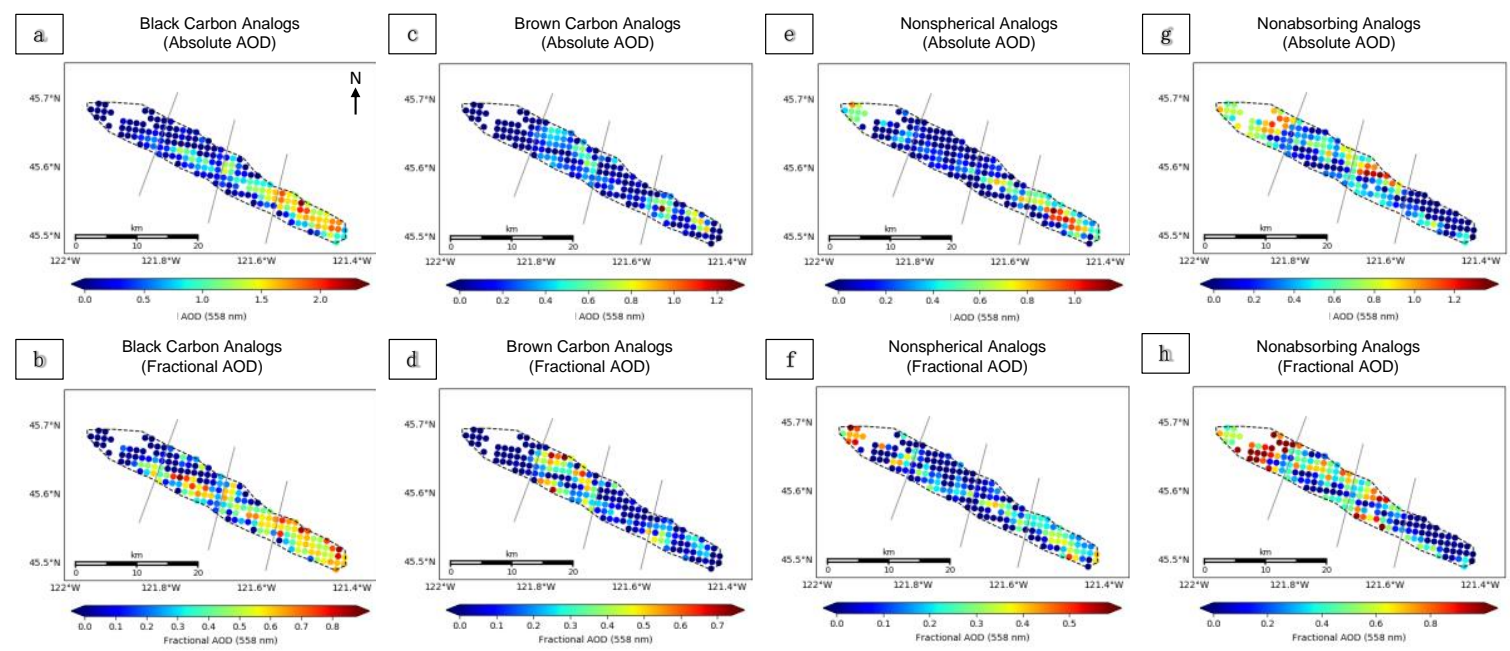

Figure 5. The absolute and fractional AOD of various MISR components for the Government Flats Complex Fire on 21 August 2013, where (a,b) are the sum of all "flat," i.e., BC-like components, (c,d) are the sum of all "steep," i.e., BrC-like components, $(\mathbf{e}, \mathbf{f})$ are the non-spherical dust-like components, and $(\mathbf{g}, \mathbf{h})$ are the sum of all non-light-absorbing components.

Table 5. MISR-observed particle properties for the Government Flats Complex Fire. AOD_aerosol optical depth; ANG-Ångström exponent.

\begin{tabular}{cccccc}
\hline \multicolumn{2}{c}{ Plume Region: } & Near-Source (I) & $\begin{array}{c}\text { Near-Downwind } \\
\text { (II) }\end{array}$ & $\begin{array}{c}\text { Mid-Downwind } \\
\text { (III) }\end{array}$ & $\begin{array}{c}\text { Far Downwind } \\
\text { (IV) }\end{array}$ \\
\hline \multirow{2}{*}{$\mathrm{AOD}$} & mean $\pm \sigma$ & $2.222 \pm 0.7840$ & $1.556 \pm 0.6195$ & $0.9851 \pm 0.2856$ & $1.020 \pm 0.2164$ \\
& median & 2.281 & 1.653 & 0.8913 & 1.007 \\
\hline \multirow{2}{*}{$\mathrm{ANG}$} & mean $\pm \sigma$ & $1.541 \pm 0.3800$ & $1.319 \pm 0.3234$ & $1.824 \pm 0.3106$ & $1.042 \pm 0.3272$ \\
& median & 1.583 & 1.293 & 1.822 & 1.024 \\
\hline \multirow{2}{*}{$\mathrm{SSA}$} & mean $\pm \sigma$ & $0.8641 \pm 0.02926$ & $0.9251 \pm 0.03960$ & $0.9154 \pm 0.04117$ & $0.9688 \pm 0.03889$ \\
& median & 0.8639 & 0.9217 & 0.9229 & 0.9802 \\
\hline \multirow{2}{*}{$\mathrm{BC}^{\text {a,b }}$} & mean $\pm \sigma$ & $0.5606 \pm 0.1681$ & $0.3649 \pm 0.2186$ & $0.2727 \pm 0.2546$ & $0.09674 \pm 0.1661$ \\
& median & 0.5852 & 0.4156 & 0.2403 & 0 \\
\hline \multirow{2}{*}{$\mathrm{BrC}^{\mathrm{a}, \mathrm{c}}$} & mean $\pm \sigma$ & $0.1260 \pm 0.1304$ & $0.08067 \pm 0.1106$ & $0.3024 \pm 0.2102$ & $0.02564 \pm 0.08594$ \\
& median & 0.08545 & 0.03358 & 0.3049 & 0 \\
\hline \multirow{2}{*}{ Non-absorbing a,d } & mean $\pm \sigma$ & $0.1069 \pm 0.1726$ & $0.4434 \pm 0.2915$ & $0.3498 \pm 0.2547$ & $0.6914 \pm 0.2948$ \\
& median & 0 & 0.4440 & 0.3835 & 0.7383 \\
\hline \multirow{2}{*}{ Non-spherical a,e } & mean $\pm \sigma$ & $0.2064 \pm 0.1307$ & $0.1110 \pm 0.1253$ & $0.07516 \pm 0.09498$ & $0.1863 \pm 0.1984$ \\
& median & 0.2119 & 0.05470 & 0.0158 & 0.08771 \\
\hline
\end{tabular}

${ }^{a}$ In terms of fraction of total AOD (0 to 1$){ }^{b}{ }^{b}$ The combined total all spectrally flat components, which are meant to represent black carbon; ${ }^{\mathrm{c}}$ The combined total of all spectrally steep components, which are meat to represent brown carbon; ${ }^{\mathrm{d}}$ The combined total of all non-absorbing components; ${ }^{\mathrm{e}}$ The only non-spherical component, meant to represent dust or soil.

The satellite and in situ measurements are substantially similar in their characterization of particle property evolution as a function of smoke age. In both cases, particle absorption systematically decreases downwind, accompanied by a transition from $\mathrm{BC}$ to $\mathrm{BrC}$ particle-type analogues as the dominant light-absorbing aerosol. Significantly smaller particles appear in region III and partway into region IV, between 48 and 90 min of aging. However, the MISR-retrieved particle sizes for smoke 
between 24 and $48 \mathrm{~min}$ in age (region II) are larger than those near the source (although still fine-mode), whereas the aircraft observes the opposite trend. Moreover, unlike the aircraft measurements, MISR indicates that particles in region III are "small" in size, whereas the aircraft measures "very small" particles (Table 3). Lastly, MISR coverage continues past $90 \mathrm{~min}$ in age, observing region IV, where the retrieval results indicate particles eventually appear somewhat coarser in size and significantly non-spherical. Despite these differences, both observation sets indicate that, overall, from the source until $~ 78$ min of aging, most of the plume comprises a majority of small, very small, and medium particles, with monotonically decreasing light absorption downwind.

Due to the comprehensive coverage, the MISR observations provide greater context for assessing the aerosol aging mechanisms that are suggested by the in situ data analysis. In region II, the increased REPS is in contrast with the decrease in particle size observed in situ. This may be explained by the difference in vertical sampling, as the aircraft measures at a single altitude, whereas the satellite observes the entire column. Column aerosol loading is dominated by the smoke plume in this case, but the plume is at least $0.75 \mathrm{~km}$ thick (Figure $4 \mathrm{~b}$ ); thus, measurements at a single elevation might not be representative. This would bolster the idea that gravitational settling is playing a role in this region. It is also possible that particle hydration, condensation of gaseous components onto existing particles, and/or particle aggregation are acting to increase particle size. The observed increase in relative humidity in this region (see Supplementary Materials, Figure S2) points toward hydration in particular, and the smaller sizes observed by the aircraft can be explained by differences in horizontal and possibly also vertical sampling. Aerosol oxidation is also acting in this region, as indicated by the increased oxidation values seen in Figure $2 b$ and supported by the increased hygroscopicity seen in Figure 2e, as well as the decreased REPA in the MISR retrievals (Figure 4f).

In region III, there is strong in situ evidence for high levels of aerosol oxidation, leading to the formation of $\mathrm{BrC}$ either from SOA production (via the nucleation of new particles) or from the deposition of organic material onto BC particles, increasing hygroscopicity and decreasing light absorption. The aircraft does not observe strong changes in particle light absorption, as would be expected with these processes, although this could be due to limited sampling (Figure 2a). MISR does appear to see the expected increase in SSA (Figure 4f), at least along the northern part of the plume in this region. The main particle-type feature of region III is the dramatic decrease in REPS, accompanied by a decrease in total-column AOD. It is unclear from the limited in situ sampling (Figure 3c) whether medium particles are actually lost from the column here. However, region III begins about $30 \mathrm{~km}$ downwind of the source, and the MISR stereo height profile indicates that the plume descends toward the surface at about this distance (Figure $4 \mathrm{~b}$ ), suggesting selective, large-particle deposition is possible. This is supported by a decrease in the total-column AOD for medium-sized particles between regions II and III (Figure S3, Supplementary Materials). In addition, both absolute and fractional increases in small aerosol AOD are observed, strongly suggesting the formation of new particles. The dramatic increase in the CO-normalized aerosol concentrations in the aircraft data further supports this conclusion, as does the increase in both the absolute and the fractional BrC AOD observed by MISR. The formation of weakly absorbing organic aerosols $(\mathrm{BrC})$ would also explain why SSA does not change more dramatically in this region.

Although the aircraft did not observe region IV, MISR points to potential aging mechanisms occurring here as well. Most notably, there is an increase in REPS, accompanied by decreasing MINX plume heights. Both the absolute and the fractional AOD of large and medium aerosols increase, suggesting that not only do small and very small particles disappear, but medium and large particles are being added (Figure S3, Supplementary Materials). At such a long downwind distance and with low overall AOD (Figure 4d), it is unlikely that particle aggregation is occurring in this region. Particle hydration might be involved, although the increase in non-spherical particles is not likely explained by this. Rather, these retrieval results might be due to a lack of larger, spherical, weakly absorbing particles in the aerosol climatology included in the MISR algorithm (Table 2), and, from a single satellite snapshot, we cannot rule out temporal changes at the smoke source. 


\subsection{Brief Summary of the Government Flats Smoke Plume Analysis}

Overall, the satellite-retrieved particle properties are relatively well supported by the in situ observations, with minor disparities that can be explained by measurement uncertainty and sampling differences. Together, the data indicate that (1) there is a near-source region of high AOD with a mixture of dark, mostly spherical, small-medium particles, with light absorption dominated by BC, (2) there is an adjacent region downwind with reduced $\mathrm{AOD}$ comprising brighter, slightly larger particles that are less BC-like, (3) there is a subsequent downwind region where AOD is reduced further, with significantly smaller particles that are brighter in nature and akin to $\mathrm{BrC}$, and (4) there is a region at the nominal end of the plume with relatively low AOD, high SSA, and a significant fraction of larger, possibly non-spherical particles.

Our interpretation of the RA results parallels the atmospheric-aerosol interactions suggested by the in situ data. Through column-integrated particle-type retrievals and plume stereo heights, the preferential gravitational settling of larger particles is supported in regions II and III. Furthermore, decreased REPA throughout the length of the plume bolsters the idea of particle oxidation and/or hydration in regions II and III. Lastly, a sharp decrease in REPS in region III accompanied by a dramatic increase in $\mathrm{BrC}$ particle AOD strongly supports the idea of new-particle SOA formation here, although the RA results alone cannot rule out condensation of gaseous compounds onto existing particles.

\subsection{Secondary Comparisons: Using Non-Coincident RA and In Situ Observations}

In the previous section, we investigated the effectiveness of the MISR RA as a tool for retrieving BB smoke particle properties, using near-coincident in situ data for validation. We also demonstrated how the RA can go further in describing plume particle properties by providing critical context for the aircraft observations. Here, we briefly summarize the results obtained by comparing MISR retrievals with BBOP data from two flights $\sim 1$ day prior to and $\sim 1$ day after the satellite overpass. This builds upon the results shown in the previous sections and allows us to explore the utility of the RA for characterizing non-coincident observations (more complete results for these two cases are given in the Supplementary Materials). The observed differences between the datasets illustrate the variable nature of BB plume dynamics and particle properties on time scales longer than a few hours, and they further highlight the value of combining satellite and in situ observations where possible to understand plume development more deeply. As such, combining multiple particle property observations, with different sensitivities and under different conditions, as well as with different spatial resolutions and coverage, creates a more complete picture of plume composition and evolution. Below are highlights from these comparisons, and we present detailed written and graphical analyses in the Supplementary Materials (Figures S4-S10 for the Colockum Tarps Fire and Figures S11-S17 for the Douglas Complex Fire).

\subsubsection{The Colockum Tarps Fire: Aircraft Observations Preceding Satellite Observations}

The Colockum Tarps Fire, first ignited due to human causes, burned from 25 July 2013 through 15 August 2013 in southern central Washington [64]. The 26 July 2013 BBOP research flight and the subsequent 27 July MISR overpass observed the resulting smoke plume. Taken together, the satellite and in situ observations describe a plume with fine-mode, highly absorbing particles near the source that become brighter downwind, although the MISR RA observes slightly smaller particles overall than the CAS and PCASP data. From the available data, the main inferences we draw about particle evolution in the Colockum Tarps Fire plumes are that the near-source aerosols tend to be smaller and more light-absorbing than downwind. Plume dilution seems to be independent of particle size, as MISR-retrieved effective particle size (REPS) does not decrease systematically downwind, and the aircraft CO-normalized aerosol concentration does not change significantly either. Aerosol oxidation is a factor in aging based on the in situ data and is likely also the explanation for a downwind increase in particle SSA observed by MISR the following day. Unlike the Government Flats fire plume, on both days, the Colockum Tarps plume retains areas of high BC fraction over the entire plume extent. 
As particle properties vary non-uniformly with distance from the source on length scales under $10 \mathrm{~km}$ in this plume, it seems likely that the primary smoke emissions from this fire varied on time scales shorter than an hour.

\subsubsection{The Douglas Complex Fire: Satellite Observations Preceding Aircraft Observations}

The Douglas Complex fire was a large system originally comprised of dozens of lightning-sparked fires that ignited on 26 July 2013 and burned through 19 August 2013 in southern coastal Oregon [63]. The 5 August 2013 MISR overpass and the subsequent 6 August BBOP research flight observed the smoke plumes that were produced. The combined information from the satellite and aircraft data suggest small-medium particle sizes in the thickest parts of the plume and very small or small particles in the surrounding smoke, although the RA retrieves overall slightly larger particles than the aircraft data on the previous day, and also finds a significant AOD contribution from large particles in the plume core. Particles near the source are moderately light-absorbing as seen by MISR, but are brighter the next day during aircraft flight operations, when the fire appears to be a bit more active in the imagery. The horizontal structure of this plume suggests that the smoke observed here is stagnant, having piled up and just spread out locally due to low wind speeds, while undergoing atmospheric processing. This is supported by the presence of larger particle sizes in the core on both days, as piled-up smoke could facilitate particle coagulation, condensation that leads to deposition of coatings on existing particles, and possibly particle hydration from fire-generated water vapor in a cooling plume. The increased CO-normalized $\mathrm{CCN}$ and aerosol concentrations outside the core region suggest possible SOA formation via the nucleation of new particles in the surroundings, where the fraction of very small particles is higher.

\section{Conclusions}

The BBOP data allow us to explore the strengths and limitations of the satellite data for characterizing wildfire smoke plume extent and particle properties. Where near-coincident data were acquired, the MISR-retrieved particle properties and those measured in situ are similar, showing consistent spatial patterns, with measurement uncertainty and sampling differences easily accounting for the observed differences. The results also demonstrate smoke-plume evolution generally consistent with previous modeling studies (e.g., References $[65,66]$ ), but providing extensive observations of a number of key smoke-plume properties not previously obtained from remote-sensing; these could be used to refine modeling options for different types of fires, globally. For the three cases analyzed here, the satellite and in situ data both captured the similarities and differences in plume structure, the relationships between denser, near-source smoke and more oxidized, less light-absorbing particles downwind, and the scales over which these transitions occurred. Furthermore, despite some limitations, the use of the MISR RA in conjunction with non-coincident in situ measurements allows for a more comprehensive analysis of plume particle properties and presents a method for studying particle aging on larger spatial and longer temporal scales, where satellite coverage is acquired but aircraft data are lacking.

The in situ data offer chemical and microphysical detail, such as the degree of particle oxidation and the specific distribution of particle sizes, as well as particle concentrations, which cannot be obtained from available satellite observations. However, the satellite snapshots offer maps of qualitative particle properties and extensive coverage, which sometimes capture aspects of the plume missed by the aircraft transects. For example, differences in plume structure among the three cases presented here were captured most effectively by the whole-plume MISR observations: the systematic change in AOD and particle properties along the length of the Government Flats plume, the patchy and more variable particle property distribution along the Colockum Tarps plume, and the seemingly stagnant pile-up of smoke particles for the Douglas Complex plume. As such, the satellite data provide the context needed to derive relationships among plume elements of different ages, making it possible to 
infer attributes of plume-particle evolution. Furthermore, MISR has obtained global coverage about once per week for over 20 years, providing a vast trove of smoke-plume observations for further study.

Future work will involve applying MISR plume height and particle property retrievals to a wide variety of cases that are less well constrained by other observations. Statistical analysis of plume particle properties from a range of BB events, focusing on the apparent changes in particle size, SSA, and SSA spectral dependence, should improve our understanding of different sources, as well as of different aging mechanisms within and between smoke plumes. Such insight represents new territory in aerosol studies and can contribute to improving climate and air quality modeling.

Supplementary Materials: The following are available online at http://www.mdpi.com/2072-4292/12/5/769/s1: Figure S1: Government Flats MISR-MINX wind vectors; Figure S2: Aircraft-observed relative humidity for the Government Flats Complex Fire; Figure S3: MISR-observed particle sizes for the Government Flats Complex Fire; Figure S4: Aircraft and satellite views of the Colockum Tarps Fire; Figure S5: Aircraft chemical and radiative observations from the Colockum Tarps Fire; Figure S6: Aircraft-observed particle sizes for the Colockum Tarps Fire; Figure S7: Aircraft-observed black carbon particle size for the Colockum Tarps Fire; Figure S8: MISR-observed plume heights and particle properties for the Colockum Tarps Fire; Figure S9: MISR-observed particle sizes for the Colockum Tarps Fire; Figure S10: MISR-observed particle types for the Colockum Tarps Fire; Figure S11: Aircraft and satellite views of the Douglas Complex Fire; Figure S12: MISR-observed plume heights and particle properties for the Douglas Complex Fire; Figure S13: MISR-observed particle sizes for the Douglas Complex Fire; Figure S14: MISR-observed particle types for the Douglas Complex Fire; Figure S15: Aircraft chemical and radiative observations from the Douglas Complex Fire; Figure S16: Aircraft-observed particle sizes for the Douglas Complex Fire; Figure S7: Aircraft-observed black carbon particle size for the Douglas Complex Fire. Text providing detailed analysis of the Government Flats, Colockum Tarps, and Douglas Complex fire plumes is included in the Supplement, along with the figures.

Author Contributions: The project was first conceptualized by R.K., and the development and design of the methodology were a collaboration between R.K. and K.J.N. The RA algorithm used in this project was developed by R.K. and J.L., and is supported by J.L., K.J.N. developed the tools used to analyze and visualize the results of both the RA and in situ data. Formal analysis of results was conducted by K.J.N. and R.K., who together wrote the original draft. Reviewing and editing were conducted by A.S., Z.L., and L.K., R.K. also provided supervision and project administration. All authors read and agreed to the published version of the manuscript.

Funding: The work of K.T. Junghenn Noyes is supported in part by a grant from the Maryland Space Grant Consortium under Richard C. Henry and Matt Collinge. The work of R.A. Kahn and J.A. Limbacher is supported in part by NASA's Climate and Radiation Research and Analysis Program under Hal Maring, NASA's Atmospheric Composition Program under Richard Eckman, and the EOS Terra Project under Kurtis Thome. The work of $Z$. $\mathrm{Li}$ is supported by a NASA grant (NNX16AN61G). K.T. Junghenn Noyes also receives partial support from the programs that cover R. Kahn and Z. Li. L.I. Kleinman and A.J. Sedlacek III were supported through the US DOE Office of Biological and Environmental Sciences (OBER) Atmospheric Research Program (ASR) under contract DE-SC0012704 (BNL).

Acknowledgments: The authors recognize the DOE Atmospheric Radiation Measurement (ARM) Climate Research program and facility for both the support to carry out the BBOP campaign and the use of the G-1 research aircraft. We also thank the BBOP instrument PI's Fan Mei (CCN counter, Pacific Northwest National Laboratory), Duli Chand (PSAP and nephelometer, Pacific Northwest National Laboratory), William Arnott (PAS, University of Nevada Reno), Jason Tomlinson, (CAS and PCASP, Pacific Northwest National Laboratory), and Stephen Springston (trace gas instrument suite, Brookhaven National Laboratory). Arthur Sedlacek was responsible for the SP2 data. We further acknowledge Bob Yokelson (University of Montana) for helpful discussions on fire chemistry, G. Thomas Arnold (NASA Goddard Space Flight Center) for assistance with image processing, and Jaewha Lee (NASA Goddard Space Flight Center) for helpful information on the use of his non-spherical particle optical model.

Conflicts of Interest: The authors declare no conflicts of interest.

\section{References}

1. Colarco, P.R.; Schoeberl, M.R.; Doddridge, B.G.; Marufu, L.T.; Torres, O.; Welton, E.J. Transport of Smoke from Canadian Forest Fires to the Surface near Washington, D.C.: Injection Height, Entrainment, and Optical Properties. J. Geophys. Res. 2004, 109. [CrossRef]

2. Kahn, R.A.; Chen, Y.; Nelson, D.L.; Leung, F.-Y.; Li, Q.; Diner, D.J.; Logan, J.A. Wildfire Smoke Injection Heights: Two Perspectives from Space. Geophys. Res. Lett. 2008, 35, L04809. [CrossRef] 
3. Warner, J.; Twomey, S. The Production of Cloud Nuclei by Cane Fires and the Effect on Cloud Droplet Concentration. J. Atmos. Sci. 1967, 24, 704-706. [CrossRef]

4. Hobbs, P.V.; Radke, L.F. Cloud Condensation Nuclei from a Simulated Forest Fire. Science 1969, 163, $279-280$. [CrossRef]

5. Kaufman, Y.J.; Fraser, R.S. The Effect of Smoke Particles on Clouds and Climate Forcing. Science 1997, 277, 1636-1639. [CrossRef]

6. Albrecht, B.A. Aerosols, Cloud Microphysics, and Fractional Cloudiness. Science 1989, 245, 1227-1230. [CrossRef]

7. Dubovik, O.; Holben, B.; Eck, T.F.; Smirnov, A.; Kaufman, Y.J.; King, M.D.; Tanre, D.; Slutsker, I. Variability of Absorption and Optical Properties of Key Aerosol Types Observed in Worldwide Locations. J. Atmos. Sci. 2002, 59, 19. [CrossRef]

8. Chen, W.-T.; Kahn, R.A.; Nelson, D.; Yau, K.; Seinfeld, J.H. Sensitivity of Multiangle Imaging to the Optical and Microphysical Properties of Biomass Burning Aerosols. J. Geophys. Res. 2008, 113, D10203. [CrossRef]

9. Eck, T.F.; Holben, B.N.; Reid, J.S.; O’Neill, N.T.; Schafer, J.S.; Dubovik, O.; Smirnov, A.; Yamasoe, M.A.; Artaxo, P. High Aerosol Optical Depth Biomass Burning Events: A Comparison of Optical Properties for Different Source Regions. Geophys. Res. Lett. 2003, 30. [CrossRef]

10. Shi, S.; Cheng, T.; Gu, X.; Guo, H.; Wu, Y.; Wang, Y. Biomass Burning Aerosol Characteristics for Different Vegetation Types in Different Aging Periods. Environ. Int. 2019, 126, 504-511. [CrossRef] [PubMed]

11. Chakrabarty, R.K.; Moosmüller, H.; Chen, L.-W.A.; Lewis, K.; Arnott, W.P.; Mazzoleni, C.; Dubey, M.K.; Wold, C.E.; Hao, W.M.; Kreidenweis, S.M. Brown Carbon in Tar Balls from Smoldering Biomass Combustion. Atmos. Chem. Phys. 2010, 10, 6363-6370. [CrossRef]

12. Chakrabarty, R.K.; Gyawali, M.; Yatavelli, R.L.N.; Pandey, A.; Watts, A.C.; Knue, J.; Chen, L.-W.A.; Pattison, R.R.; Tsibart, A.; Samburova, V.; et al. Brown Carbon Aerosols from Burning of Boreal Peatlands: Microphysical Properties, Emission Factors, and Implications for Direct Radiative Forcing. Atmos. Chem. Phys. 2016, 16, 3033-3040. [CrossRef]

13. Petrenko, M.; Kahn, R.; Chin, M.; Soja, A.; Kucsera, T.; Harshvardhan. The Use of Satellite-Measured Aerosol Optical Depth to Constrain Biomass Burning Emissions Source Strength in the Global Model GOCART. J. Geophys. Res. 2012, 117. [CrossRef]

14. Samset, B.H.; Stjern, C.W.; Andrews, E.; Kahn, R.A.; Myhre, G.; Schulz, M.; Schuster, G.L. Aerosol Absorption: Progress Towards Global and Regional Constraints. Curr. Clim. Chang. Rep. 2018, 4, 65-83. [CrossRef] [PubMed]

15. Akagi, S.K.; Craven, J.S.; Taylor, J.W.; McMeeking, G.R.; Yokelson, R.J.; Burling, I.R.; Urbanski, S.P.; Wold, C.E.; Seinfeld, J.H.; Coe, H.; et al. Evolution of Trace Gases and Particles Emitted by a Chaparral Fire in California. Atmos. Chem. Phys. 2012, 12, 1397-1421. [CrossRef]

16. Zhou, S.; Collier, S.; Jaffe, D.A.; Briggs, N.L.; Hee, J.; Sedlacek, A.J., III; Kleinman, L.; Onasch, T.B.; Zhang, Q. Regional Influence of Wildfires on Aerosol Chemistry in the Western US and Insights into Atmospheric Aging of Biomass Burning Organic Aerosol. Atmos. Chem. Phys. 2017, 17, 2477-2493. [CrossRef]

17. Kleinman, L.I.; Sedlacek, A.J. Biomass Burning Observation Project Science Plan; DOE/SC-ARM; Brookhaven National Laboratory (BNL): Upton, NY, USA, 2013.

18. Kleinman, L.I.; Sedlacek, A.J. Biomass Burning Observation Project (BBOP): Final Campaign Report; DOE ARM Climate Research Facility: Washington, DC, USA, 2016.

19. Toon, O.B.; Maring, H.; Dibb, J.; Ferrare, R.; Jacob, D.J.; Jensen, E.J.; Luo, Z.J.; Mace, G.G.; Pan, L.L.; Pfister, L.; et al. Planning, Implementation, and Scientific Goals of the Studies of Emissions and Atmospheric Composition, Clouds and Climate Coupling by Regional Surveys (SEAC ${ }^{4}$ RS) Field Mission. J. Geophys. Res. Atmos. 2016, 121, 4967-5009. [CrossRef]

20. Forrister, H.; Liu, J.; Scheuer, E.; Dibb, J.; Ziemba, L.; Thornhill, K.L.; Anderson, B.; Diskin, G.; Perring, A.E.; Schwarz, J.P.; et al. Evolution of Brown Carbon in Wildfire Plumes. Geophys. Res. Lett. 2015, 42, 4623-4630. [CrossRef]

21. Sedlacek, A.J., III; Buseck, P.R.; Adachi, K.; Onasch, T.B.; Springston, S.R.; Kleinman, L. Formation and Evolution of Tar Balls from Northwestern US Wildfires. Atmos. Chem. Phys. 2018, 18, 11289-11301. [CrossRef] 
22. Adachi, K.; Sedlacek, A.J.; Kleinman, L.; Springston, S.R.; Wang, J.; Chand, D.; Hubbe, J.M.; Shilling, J.E.; Onasch, T.B.; Kinase, T.; et al. Spherical Tarball Particles Form through Rapid Chemical and Physical Changes of Organic Matter in Biomass-Burning Smoke. Proc. Natl. Acad. Sci. USA 2019, 116, 19336-19341. [CrossRef]

23. Feng, Y.; Ramanathan, V.; Kotamarthi, V.R. Brown Carbon: A Significant Atmospheric Absorber of Solar Radiation? Atmos. Chem. Phys. 2013, 13, 8607-8621. [CrossRef]

24. Jethva, H.; Torres, O. Satellite-Based Evidence of Wavelength-Dependent Aerosol Absorption in Biomass Burning Smoke Inferred from Ozone Monitoring Instrument. Atmos. Chem. Phys. 2011, 11, 10541-10551. [CrossRef]

25. Konovalov, I.B.; Beekmann, M.; Berezin, E.V.; Formenti, P.; Andreae, M.O. Probing into the Aging Dynamics of Biomass Burning Aerosol by Using Satellite Measurements of Aerosol Optical Depth and Carbon Monoxide. Atmos. Chem. Phys. 2017, 17, 4513-4537. [CrossRef]

26. Kahn, R.A. A global perspective on wildfires. EOS Am. Geophys. Union 2020, 101. [CrossRef]

27. Nelson, D.; Garay, M.; Kahn, R.; Dunst, B. Stereoscopic Height and Wind Retrievals for Aerosol Plumes with the MISR INteractive EXplorer (MINX). Remote Sens. 2013, 5, 4593-4628. [CrossRef]

28. Limbacher, J.A.; Kahn, R.A. MISR Research-Aerosol-Algorithm Refinements for Dark Water Retrievals. Atmos. Meas. Technol. 2014, 7, 3989-4007. [CrossRef]

29. Limbacher, J.A.; Kahn, R.A. Updated MISR Over-Water Research Aerosol Retrieval Algorithm-Part 2: A Multi-Angle Aerosol Retrieval Algorithm for Shallow, Turbid, Oligotrophic, and Eutrophic Waters. Atmos. Meas. Technol. 2019, 12, 675-689. [CrossRef]

30. Kahn, R.A.; Limbacher, J. Eyjafjallajökull Volcano Plume Particle-Type Characterization from Space-Based Multi-Angle Imaging. Atmos. Chem. Phys. 2012, 12, 9459-9477. [CrossRef]

31. Scollo, S.; Kahn, R.A.; Nelson, D.L.; Coltelli, M.; Diner, D.J.; Garay, M.J.; Realmuto, V.J. MISR Observations of Etna Volcanic Plumes. J. Geophys. Res. 2012, 117. [CrossRef]

32. Flower, V.J.B.; Kahn, R.A. Distinguishing Remobilized Ash From Erupted Volcanic Plumes Using Space-Borne Multiangle Imaging: Remobilized Ash Plumes. Geophys. Res. Lett. 2017, 44, 10772-10779. [CrossRef]

33. Flower, V.J.B.; Kahn, R.A. Karymsky Volcano Eruptive Plume Properties Based on MISR Multi-Angle Imagery and the Volcanological Implications. Atmos. Chem. Phys. 2018, 18, 3903-3918. [CrossRef] [PubMed]

34. Flower, V.J.B.; Kahn, R.A. Interpreting the Volcanological Processes of Kamchatka, Based on Multi-Sensor Satellite Observations. Remote Sens. Environ. 2020, 237, 111585. [CrossRef]

35. Kahn, R.A.; Gaitley, B.J. An Analysis of Global Aerosol Type as Retrieved by MISR: MISR Aerosol Type. J. Geophys. Res. Atmos. 2015, 120, 4248-4281. [CrossRef]

36. Diner, D.J.; Beckert, J.C.; Reilly, T.H.; Bruegge, C.J.; Conel, J.E.; Kahn, R.A.; Martonchik, J.V.; Ackerman, T.P.; Davies, R.; Gerstl, S.A.W.; et al. Multi-Angle Imaging SpectroRadiometer (MISR) Instrument Description and Experiment Overview. IEEE Trans. 1998, 36, 1072-1087. [CrossRef]

37. Nelson, D.L.; Chen, Y.; Kahn, R.A.; Diner, D.J.; Mazzoni, D. Example Applications of the MISR INteractive EXplorer (MINX) Software Tool to Wildfire Smoke Plume Analyses. Remote Sens. Fire Sci. Appl. 2008, 708909. [CrossRef]

38. Val Martin, M.; Logan, J.A.; Kahn, R.A. Smoke Injection Heights from Fires in North America: Analysis of 5 Years of Satellite Observations. Atmos. Chem. Phys. 2010, 10, 1491-1510. [CrossRef]

39. Val Martin, M.; Kahn, R.; Tosca, M. A Global Analysis of Wildfire Smoke Injection Heights Derived from Space-Based Multi-Angle Imaging. Remote Sens. 2018, 10, 1609. [CrossRef]

40. Tosca, M.G.; Randerson, J.T.; Zender, C.S.; Nelson, D.L.; Diner, D.J.; Logan, J.A. Dynamics of Fire Plumes and Smoke Clouds Associated with Peat and Deforestation Fires in Indonesia. J. Geophys. Res. 2011, 116, D08207. [CrossRef]

41. Flower, V.J.B.; Kahn, R.A. Assessing the Altitude and Dispersion of Volcanic Plumes Using MISR Multi-Angle Imaging from Space: Sixteen Years of Volcanic Activity in the Kamchatka Peninsula, Russia. J. Volcanal. Geoth. Res. 2017, 337, 1-15. [CrossRef]

42. Yu, Y.; Kalashnikova, O.V.; Garay, M.J.; Lee, H.; Notaro, M. Identification and Characterization of Dust Source Regions Across North Africa and the Middle East Using MISR Satellite Observations. Geophys. Res. Lett. 2018, 45, 6690-6701. [CrossRef]

43. Vernon, C.J.; Bolt, R.; Canty, T.; Kahn, R.A. The Impact of MISR-Derived Injection Height Initialization on Wildfire and Volcanic Plume Dispersion in the HYSPLIT Model. Atmos. Meas. Technol. 2018, 11, 6289-6307. [CrossRef] 
44. Kahn, R.A.; Gaitley, B.J.; Garay, M.J.; Diner, D.J.; Eck, T.; Smirnov, A.; Holben, B.N. Multiangle Imaging SpectroRadiometer global aerosol product assessment by comparison with the Aerosol Robotic Network. J. Geophys. Res. 2010, 115, D23209. [CrossRef]

45. Lee, J.; Hsu, N.C.; Sayer, A.M.; Bettenhausen, C.; Yang, P. AERONET-Based Nonspherical Dust Optical Models and Effects on the VIIRS Deep Blue/SOAR Over Water Aerosol Product: Dust Optical Models for Deep Blue/SOAR. J. Geophys. Res. Atmos. 2017, 122, 10384-10401. [CrossRef] [PubMed]

46. Andreae, M.O.; Gelencser, A. Black Carbon or Brown Carbon? The Nature of Light-Absorbing Carbonaceous Aerosols. Atmos. Chem. Phys. 2006, 18, 3419-3463. [CrossRef]

47. Lyapustin, A.; Wang, Y. MODIS Multi-Angle Implementation of Atmospheric Correction (MAIAC) Data User's Guide; NASA: Greenbelt, MD, USA, 2018.

48. Chand, D.; Schmid, B. Nephelometer PSAP, BBOP. Atmospheric Radiation Measurement Climate Research Facility. 2015. Available online: https://www.osti.gov/biblio/1461871-nephelometer-psap-bbop (accessed on 30 January 2020). [CrossRef]

49. Anderson, T.L.; Ogren, J.A. Determining Aerosol Radiative Properties Using the TSI 3563 Integrating Nephelometer. Aerosol Sci. Technol. 1998, 29, 57-69. [CrossRef]

50. Bond, T.C.; Anderson, T.L.; Campbell, D. Calibration and Intercomparison of Filter-Based Measurements of Visible Light Absorption by Aerosols. Aerosol Sci. Technol. 1999, 30, 582-600. [CrossRef]

51. Ogren, J.A. Comment on "Calibration and Intercomparison of Filter-Based Measurements of Visible Light Absorption by Aerosols". Aerosol Sci. Technol. 2010, 44, 589-591. [CrossRef]

52. Springston, S.R. Particle Soot Absorption Photometer (PSAP) Instrument Handbook; DOE ARM Climate Research Facility: Washington, DC, USA, 2018.

53. Arnott, W.P. PAS, BBOP. Atmospheric Radiation Measurement Climate Research Facility. 2013. Available online: https://adc.arm.gov/discovery/\#v/results/s/s::bbop (accessed on 20 December 2019).

54. Sedlacek, A.; Lee, J. Photothermal Interferometric Aerosol Absorption Spectrometry. Aerosol Sci. Technol. 2007, 41, 1089-1101. [CrossRef]

55. Reid, J.S.; Koppmann, R.; Eck, T.F.; Eleuterio, D.P. A Review of Biomass Burning Emissions Part II: Intensive Physical Properties of Biomass Burning Particles. Atmos. Chem. Phys. 2005, 28, 799-825. [CrossRef]

56. Uin, J. Cloud Condensation Nuclei Particle Counter Instrument Handbook; DOE ARM Climate Research Facility: Washington, DC, USA, 2016.

57. Mei, F. AAF-CCN, BBOP. Atmospheric Radiation Measurement Climate Research Facility. 2013. Available online: https://adc.arm.gov/discovery/\#v/results/s/s::bbop (accessed on 20 September 2019).

58. Yokelson, R.J.; Crounse, J.D.; DeCarlo, P.F.; Karl, T.; Urbanski, S.; Atlas, E.; Campos, T.; Shinozuka, Y.; Kapustin, V.; Clarke, A.D.; et al. Emissions from Biomass Burning in the Yucatan. Atmos. Chem. Phys. 2009, 28, 5785. [CrossRef]

59. Kleinman, L.I.; Springston, S.R.; Daum, P.H.; Weinstein-Lloyd, J.; Alexander, M.L.; Hubbe, J.; Ortega, J.; Canagaratna, M.R.; Jayne, J. The Time Evolution of Aerosol Composition over the Mexico City Plateau. Atmos. Chem. Phys. 2008, 17, 14461-14509. [CrossRef]

60. DeCarlo, P.F.; Dunlea, E.J.; Kimmel, J.R.; Aiken, A.C.; Sueper, D.; Crounse, J.; Wennberg, P.O.; Emmons, L.; Shinozuka, Y.; Clarke, A.; et al. Fast Airborne Aerosol Size and Chemistry Measurements above Mexico City and Central Mexico during the MILAGRO Campaign. Atmos. Chem. Phys. 2008, 8, 4027-4048. [CrossRef]

61. Sedlacek, A.J. Single Particle Soot Photometers (SP2) Instrument Handbook; DOE ARM Climate Research Facility: Washington, DC, USA, 2017.

62. Sedlacek, A.J.; Lewis, E.R.; Kleinman, L.; Xu, J.; Zhang, Q. Determination of and Evidence for Non-Core-Shell Structure of Particles Containing Black Carbon Using the Single-Particle Soot Photometer (SP2). Geophys. Res. Lett. 2012, 39. [CrossRef]

63. Oregon Department of Forestry: Fires List. Available online: https:/apps.odf.oregon.gov/DIVISIONS/ protection/fire_protection/fires/FIRESlist.asp (accessed on 28 December 2019).

64. National Fire and Aviation Management: Incident Status Summary. Available online: https://fam.nwcg.gov/fam-web/hist_209/hist_r_print_209_head_2013?v_number=WA-SES-349\&v_report_ date $=08 / 18 / 2013 \& v \_h o u r=1200 \& v \_$gaid=NW (accessed on 28 December 2019). 
65. Hodshire, A.L.; Bian, Q.; Ramnarine, E.; Lonsdale, C.R.; Alvarado, M.J.; Kreidenweis, S.M.; Jathar, S.H.; Pierce, J.R. More than emissions and chemistry: Fire size, dilution, and background aerosol also greatly influence near-field biomass burning aerosol aging. J. Geophys. Res. Atmos. 2019, 124, 5589-5611. [CrossRef]

66. Konovalov, I.B.; Beekmann, M.; Golovushkin, N.A.; Andreae, M.O. Nonlinear behavior of organic aerosol in biomass burning plumes: A microphysical model analysis. Atmos. Chem. Phys. 2019, 19, 12091-12119. [CrossRef]

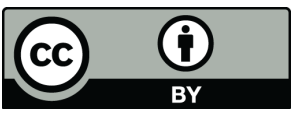

(C) 2020 by the authors. Licensee MDPI, Basel, Switzerland. This article is an open access article distributed under the terms and conditions of the Creative Commons Attribution (CC BY) license (http://creativecommons.org/licenses/by/4.0/). 